\title{
¡Coreografía, música... acción! Caracterización y patrones gestuales de los juegos de manos en castellano
}

\section{Choreography, Music... Action! Characterization and Gestural Patterns of Hand Clapping Games in Spanish}

\author{
por \\ Joanna Riera Martínez \\ Universitat Autònoma de Barcelona, España \\ jrieramar@gmail.com \\ Albert Casals Ibáñez \\ Universitat Autònoma de Barcelona, España \\ Albert.casals@uab.cat
}

Los juegos de manos son canciones populares infantiles que destacan por su transmisión a nivel mundial ya desde los años ochenta hasta la actualidad. Van acompañados de gestos que han sido estudiados y recopilados, destacando en habla inglesa a Hubbard (1982), Curtis (2004) y Gaunt (2006) y en habla castellana a Hemsy de Gainza (1996). A pesar de su interés en la literatura, no se ha estudiado la clasificación de los gestos a base de coreografías. Formando parte de una investigación de doctorado por la Universidad Autónoma de Barcelona (España) y su estadía en la Universidad Alberto Hurtado (Chile), este artículo presenta, por primera vez, el análisis de las coreografías y su relación a nivel textual y melódico de los juegos de manos en castellano centrados en una investigación profunda llevada a cabo en Chile y España. Los resultados muestran cinco estilos coreográficos distintos entre sí: la coreografía de base, la coreografía estándar, la coreografía cruzada, la coreografía de balanceo y finalmente las coreografías específicas.

Palabras clave: juegos de manos, coreografía, música popular infantil, transmisión oral, enculturación.

Hand Clapping games are popular children's songs that stand out for their worldwide diffusion since the 80s to the present. They are accompanied by gestures that have been studied and compiled, mainly by Hubbard (1982), Curtis (2004) and Gaunt (2006) in English, and Hemsy de Gainza (1996) in Spanish. Despite their interest in the literature, the classification of gestures based on choreography has not been studied. Being part of a PhD research by the Autonomous University of Barcelona (Spain) and the Alberto Hurtado University's stay (Chile), this article presents, for the first time, the analysis of the choreographies and their relationship at the textual and melodic level of hand clapping games in Spanish focused on a deep investigation carried out in Chile and Spain. The results show five different choreographic styles: the basic choreography, the standard choreography, the cross choreography, the waving rocking choreography and finally the specific choreographies.

Keywords: Hand Clapping Games, popular children's music, oral transmission, enculturation. 


\section{INTRODUCCIÓN}

$¿$ Conoces algunos juegos de manos? Esta pregunta fue formulada en el contexto de esta investigación a diferentes niños y niñas en la actualidad y en contextos de distintos continentes. Muchos de ellos lo confirmaron mostrando la ilusión ante el hecho de que estuviéramos interesados en los juegos de manos (o canciones de dar palmas, en España). Quizás esto pasa porque se sienten protagonistas y productores de estos. Nos encontramos, por tanto, en una actividad lúdica usual y asumida como propia dentro del mundo infantil y que, paradójicamente, ha atraído poco la mirada de investigadores de países iberoamericanos.

Los juegos de manos son canciones populares infantiles muy extendidas que destacan por su transmisión a nivel mundial ya desde la década de 1980 hasta la actualidad (Arleo 2001). Son canciones motrices en que dos o más participantes se colocan uno enfrente del otro o bien al lado, creando un círculo, y golpean sus manos u otras partes del cuerpo intercalando, en algunos casos, gestos descriptivos (Riera y Casals 2014: 112). Como sucede en los juegos de manos, cuando Willett (2011) analiza la performance de las canciones pop en niñas preadolescentes remarca varias estructuras involucradas en el proceso: entre ellas, el texto, la melodía y el gesto. Existen otros aspectos remarcables en la canción popular infantil en general, como son las representaciones de raza, etnicidad y género materializadas en el canto y el movimiento de percusión (Gaunt 2006).

La transmisión de los juegos de manos es oral, mediante la observación e imitación de los mayores por parte de los pequeños (Grugeon 1993) y, por lo general, se lleva a cabo de forma horizontal; es decir, entre los niños y las niñas de la misma generación en el contexto del colegio (Ackerley 2007).

Las figuras retóricas, aunque muy vinculadas con la literatura, también pueden aparecer a nivel musical y gestual. Estas "fórmulas" literarias, musicales y gestuales ayudan a embellecer y armonizar la expresión. También sirven de patrones de transmisión que facilitan el ejercicio de la memoria, gracias a sus características mnemotécnicas, y se instauran en la mente con facilidad (Burn 2014). A nivel melódico, en esencia siguen un patrón repetitivo de diseño rítmico-recitativo o bien rítmico-melódico, que puede variar durante la canción de palmas. En el caso de ser melódico, por lo general, se sirve de centros tonales en un sistema modal de cuatro o cinco niveles sonoros (Riera 2013). A nivel textual, Pelegrín (1992: 5, 51) destacó la reiteración (la repetición de palabras, la anáfora, repetición con función de estribillo, encadenamiento) y la enumeración como algunas de las figuras retóricas más usadas en los juegos y poesías infantiles. En los juegos de manos también aparece lo que la retórica clásica denomina tropos: cuando se substituye una palabra en la que se evoca una cosa sin decirla por medio de otras que hacen pensar en ella. Así como Gómez lo describe en su estudio de literatura popular en música pop, sería "la sustitución de una palabra por otra que se refiere a ella de modo traslaticio, lo que provoca automáticamente un cambio de significado y revela la necesidad literaria de crear nuevos sentidos y asociaciones de sentido" (Gómez 2004: 55).

Lo interesante en este caso es que los juegos de manos se transmiten con poca o nula intervención adulta, siendo tanto niños como niñas los creadores musicales de sus propias prácticas (Veblen, Kruse y Messenger 2018).

En la tradición oral infantil, observamos a menudo cómo los infantes son compositores de su propio repertorio musical ejerciendo de productores y reproductores, capaces de seleccionar, eliminar, adaptar y modificar sus propias narrativas musicales (Blatchford 1998; Barrett 2003, Ackerley 2007). En ellas se crea, se recrea y se reproducen reforzando las ideas de la sociedad en la que surgieron, basándose en el discurso cultural hegemónico de la sociedad en cuestión: 
La canción es una vía de endoculturación social en general, y en particular esto parece claro en la infancia, donde se moldean las mentes infantiles, cuando se figura su cultura sociopolítica y la formación de ideas político-sociales tiene lugar, entre otras cosas (Delval 1999. Citado en Fernández Poncela 2005).

Díaz redacta una interpretación personal del deseo al que aspiran las niñas y niños al oír una canción:

El deseo natural de cualquier crío, sobre todo a partir de los cinco años, es el de escuchar en el texto algo fantástico; un cuento cantado, en resumen. Las niñas, en cambio, utilizan para sus juegos, canciones como esta, en la que se respira algo de la vida real:

$$
\begin{aligned}
& \text { Me casó mi madre, } \\
& \text { chiquita y bonita, } \\
& \text { con unos amores } \\
& \text { que yo no quería } \\
& \text { (...) (Díaz 1971: 97). }
\end{aligned}
$$

Esta diferenciación es difícil de sostener hoy, al menos de forma tan simple, pero sí que es verdad que los juegos de manos a menudo "respiran algo de la vida real" y están protagonizados mayoritariamente por niñas. De hecho, en este tipo de canciones se ponen en juego y se negocian los discursos de poder imperantes. Según Fernández Poncela (2005), los discursos de poder que aparecen se basan sobre todo en cuestiones de género (amor, matrimonio, el papel de la mujer), Iglesia, Ejército y monarquía. En algunos casos, conforme al poder hegemónico; en muchos otros, subvirtiéndolo en forma de tabú o diciendo aquello que no es propio según la cultura en la que se vive.

\section{INVESTIGACIONES SOBRE JUEGOS DE MANOS}

Las actividades en torno a los juegos de manos hace tiempo que despiertan el interés de investigadores de distintas partes del mundo. Los estudios de habla inglesa generados acerca de los juegos de manos destacan la gran participación femenina, así como las relaciones de poder que aparecen en el juego (Ackerley 2007). También se proporciona información acerca de la co-construcción de identidades (Blatchford 1998) y del carácter subversivo que aparece en las letras y el juego gestual (Bhana 2011). Existe, además, literatura respecto de la construcción narrativa y su mantenimiento social (Bauer y Bauer 2007). Ackerley, en su estudio en Nueva Zelanda y en el que también hace referencia a otros países, revela que los niños utilizan cantos inventados para experimentar los límites de su vida social. Curtis (2004), por su lado, explicó que, en los recreos en los que realizó la observación de los juegos de manos, ella veía con frecuencia otras niñas más pequeñas alrededor, las que observaban y copiaban a las mayores. Por ello Curtis concluye que la performance tiene algo que ver con la reputación y la admiración de los demás respecto de las participantes. Eso explicaría que la finalidad del juego muy a menudo sea "a cuanto más veloz, mejor".

Aunque en el contexto iberoamericano existen pocas investigaciones específicas, sí que nos encontramos con varios cancioneros que recogen juegos de manos. De hecho, posiblemente la primera citación de juegos de palmas data de 1976, cuando Juan Pérez Ortega, en su recopilación Música folklórica infantil chilena, refiere que algunas canciones sirven para acompañar precisamente al juego de palmas. De todos modos, anteriormente, en 1946, Oreste Plath ya se refirió a un tipo de "canciones que cantan los niños" (Plath 1946: 219) a las que no se les dio un nombre específico y que comparten parte de la descripción dada a los juegos de manos (Riera 2013): 
Entre los juegos infantiles, se incluyen las canciones de entretenimientos, que van acompañadas de ademanes sumamente graciosos; por ejemplo, como aquellas en que se remedan oficios, se imitan movimientos de las aves. Estas canciones agradan a los niños, porque creen demostrar con ellas condiciones y cualidades imitativas. En la composición de estas rimas, que pertenecen a la literatura oral popular, se encuentran frases desprovistas de sentido común y palabras de significado desconocido a causa de la deformación que han debido sufrir. Este hecho se repite con frecuencia al tratarse de estas fórmulas (Plath, 1946: 219).

El mismo autor describe en otro texto (Plath 2009) algunos juegos de manos en Chile de forma general, en torno a los gestos y los textos que aparecen en ellas. Por otra parte, en 1999, Manuel Peña publicó una recopilación de su investigación acerca de la tradición oral en Chile (Juguemos al hilo de oro. Folclor infantil chileno), con la intención de recuperar la identidad chilena mediante el lenguaje. En esa selección aparecen, entre otros estilos musicales, algunos juegos de manos. Finalmente, en el contexto sudamericano es importante destacar dos trabajos más: por un lado, el de la reconocida autora argentina Hemsy de Gainza (1996), que tiene vocación divulgativa y está más enfocado a su uso pedagógico que a su análisis musicológico; y, por otro lado, una aportación fruto de una Beca de Cultura en Chile (Becas Fondart) en 2008, y en la que los autores trabajaron en profundidad los juegos de tradición oral chilenos (González y González 2008). Ambas aportaciones coinciden en intentar describir los gestos usados en dichos juegos. Destaca una pequeña investigación de carácter etnográfico llevada a cabo por Ferré (1993) y en la que se concluye apuntando a la función de enculturación de estos juegos, a la gran participación femenina y a la influencia de los medios de comunicación. Desde otra perspectiva, Martín Escobar (2001) hace una investigación acerca de la canción popular infantil española, contextualizando los juegos de manos en la década de los noventa con origen en los años setenta. Unos años más tarde, y combinando la perspectiva histórica con la sincrónica, Casals y Riera (2015) encontraron resultados parecidos a los juegos de manos de habla inglesa. Se describe el rol de los juegos de manos en la construcción del género de las participantes, tanto mediante los discursos que se generan en el juego como en las letras de las canciones; se muestra el tratamiento del canon y su subversión, así como el uso de palabras sin sentido que crean incoherencia en las frases de algunas de las letras. Por su parte, Romero y Romero (2013) estudiaron los juegos de manos, a modo de revisión téorica y desde una perspectiva educativa. Destacan la importancia de las estructuras a nivel corporal en la ejecución, el uso de las habilidades psicomotoras en el aprendizaje en grupo, las capacidades neuronales que explicarían su comienzo a la edad de cinco hasta los once años, y la diferenciación de géneros en la destreza en la ejecución, siendo las niñas las participantes protagonistas de este tipo de juego.

Poniendo el foco en la parte musical, se ha visto que siguen un patrón repetitivo de diseño rítmico-recitativo, o bien rítmico-melódico, que puede variar durante la canción. En el caso de ser melódico, básicamente se sirve de centros tonales en un sistema modal de cuatro o cinco niveles sonoros, destacando el intervalo de tercera menor y de cuarta (Riera 2013). Desde otra perspectiva, Bauer y Bauer (2007) afirman que hay una constante variación y adaptación de las actividades culturales al contexto social y a las necesidades de los individuos, que son claramente influenciados por las modas existentes. De esta forma, junto con la memoria histórica que atraviesa la canción tradicional y los cuentos de hadas -entre otros géneros de la cultura popular-, en los juegos de manos se entremezcla el repertorio musical de la industria discográfica, los productos comerciales e internet. De esta forma, se transforman y se reconstruyen continuamente las canciones que los niños utilizan para jugar (Veblen, Kruse y Messenger 2018). De hecho, Casals y Riera (2015) también constataron la gran importancia de la influencia de los avances tecnológicos en la comunicación, reproducción musical y audiovisual. 
En relación con la coreografía, hay tres estudios a destacar centrados en los juegos de manos anglosajones: el de Hubbard, el de Curtis y, finalmente, el de Gaunt.

Hubbard (1982) fue el primero en hacer un estudio de las coreografías, en Yorkshire. En él describió los movimientos gestuales con gráficos y analizó cinco canciones inglesas: Brambe Blushes, Suzy (dos versiones), A Sailor went to Sea y Baker's Shop.

Curtis (2004) se basó en Hubbard para llevar a cabo un estudio similar, de nuevo en Yorkshire, con un trabajo de campo entre 1999 y 2001 en varias escuelas con gran cantidad de población inmigrante de Paquistán y Bangladesh. En su estudio reveló que, en las canciones de dar palmas de lengua inglesa, generalmente aparecen tres o cuatro gestos que se repiten de forma cíclica hasta acabar la canción, y acompañando una melodía cantada. Analizando la concordancia entre el ritmo gestual, el ritmo silábico y la melodía, Curtis recalcó que el tempo fuerte del ritmo gestual no coincidía siempre con la métrica a cuatro tiempos de la melodía. En consecuencia, sugería que las niñas organizaban la parte gestual independientemente de las palabras y la melodía.

Por último, Gaunt (2006) estudia la métrica y el contrapunto que aparecen en los juegos de manos debido a su interés en el aprendizaje de polirritmias en la música popular infantil. La autora lo define como un patrón de sonidos de percusión que crean con sus cuerpos: la percusión coreográfica del cuerpo. Describe de manera narrada algunos de los gestos que también encontró Hubbard y el análisis de la canción Miss Mary Mack, para explicar el contrapunto en la que la percusión se hace con las palmas articulando el tiempo fuerte en los tiempos dos y cuatro del compás cuaternario de la melodía y marcando los tiempos débiles percutiendo sobre el propio cuerpo.

Además de las aportaciones de los investigadores anteriores, en la recopilación de juegos de manos iberoamericanos de Hemsy de Gainza se desarrolla una anotación melódicogestual mucho más exhaustiva y compleja que la de Hubbard y Curtis. La autora destacó los siguientes rasgos gestuales en los juegos de manos: a) la sincronía entre palabra y gesto; b) el realismo o la comicidad de la mímica y las onomatopeyas; c) la coordinación motriz; d) la velocidad rápida o creciente; y e) un final caprichoso, cómico o inesperado.

Como se extrae de lo anterior, la performance de los juegos de manos pasa por la coreografía, el texto y la melodía. Gaunt estaría de acuerdo en que el ritmo sincopado que se crea entre el texto y el gesto en los juegos de manos forma parte de la canción y no puede ser pensada por partes separadas, sin conocer el conjunto.

\section{PLANTEAMIENTO INVESTIGATIVO}

Una de las especificidades de estas canciones de dar palmas es que se construyen, se conservan y se experimentan histórica, social e individualmente sin el control de una institución. Por ello no podemos estudiarlas como un objeto aislado (una canción con gestos únicamente), sino como una actividad social, con una vivencia personal y de acuerdo con una construcción histórica específica. Este artículo se basa en el enfoque metodológico de Timothy Rice ${ }^{1}$ para poder estudiar los juegos de manos teniendo en cuenta el ser individual como el ejecutor y pensador del juego, el ser colectivo donde se construye el objeto en sí mediante la identificación grupal, y su ontogenia histórica por medio de la manifestación de las diferentes generaciones.

1 El enfoque metodológico de Timothy Rice (2001) permite establecer vínculos entre la construcción histórica, la conservación social y la vivencia individual de la actividad musical que se investiga. 
Este artículo presenta, por primera vez, el análisis de las coreografías y su relación a nivel textual y melódico de los juegos de manos en castellano centrados en una investigación en profundidad llevada a cabo en Santiago de Chile (centro de la ciudad, la comuna de Las Condes y la comuna de Peñalolén), en el norte de Chile (La Serena) y España (Barcelona y Cardedeu). Los objetivos trazados son: a) contextualizar la actividad musical que son los juegos de manos iberoamericanos a nivel histórico y sincrónico; b) categorizar los gestos según las combinaciones que aparecen; y c) analizar la relación entre la melodía, el texto y el gesto a partir de ejemplos concretos.

Los datos que se presentan a continuación fueron recogidos de observaciones participantes y no participantes en seis colegios entre octubre de 2018 y octubre de 2019 en el marco de una investigación profunda de doctorado. Cuatro escuelas están situadas en el contexto chileno: dos escuelas privadas en la periferia de Santiago, una de ellas es el Colegio Institución Teresiana en Las Condes y otra la escuela-granja laica llamada Maison De l'Enfance (Peñalolén); una escuela pública en el centro de Santiago de Chile, Fernando Alessandri Rodríguez, y una escuela privada en La Serena, Andrés Bello Pampa. Las otras dos escuelas están en contexto español: una escuela pública en el centro de Barcelona, Mossèn Jacint Verdaguer y, finalmente, una escuela pública en una pequeña localidad catalana llamada Cardedeu, Germans Corbella. Los infantes que han participado en esta investigación comprenden un rango etario de entre los cuatro y trece años.

Para su estudio contextual e histórico, el trabajo de campo se acompañó de nueve entrevistas semiestructuradas y siete grupos de discusión con personas nacidas entre 1929 y 2003, en el caso de Chile, y ocho grupos de discusión con personas nacidas entre 1914 y 2000, en el caso de España.

Los grupos de discusión se plantearon como entrevistas en grupo de informantes que podían ofrecer datos relevantes acerca de lo que pasaba en un determinado momento histórico. Se organizaron con personas de Santiago de Chile de diferentes comunas, nacidas más o menos en la misma década y que no necesariamente habían pasado la infancia en el mismo lugar, dándose una muestra heterogénea de territorios chilenos. Las personas entrevistadas de manera individual viven en la actualidad en la misma ciudad y pasaron su infancia en diferentes áreas de Chile. Esta heterogeneidad ayuda a poder contextualizar el inicio de los juegos de manos. Del mismo modo se construyeron grupos de discusión y entrevistas a diferentes personas nacidas y organizadas por década de nacimiento que viven hoy en Cardedeu, pero que pasaron su infancia en diferentes territorios españoles. La recogida de datos se hizo mediante grabadora y video. Después de transcribir los datos en el programa Word, se analizaron y se categorizaron usando el programa ATLAS-T 8. Por su simplicidad visual del espacio, se ha optado por usar la notación de Hubbard y Curtis para el análisis coreográfico basado en dos participantes enfrentadas. Se asume que los gestos puedan variar cuando se trate de juego grupal. Cuando ha sido necesario, se han añadido gestos que no aparecen en la propuesta de dichos autores, pero que sí los propone Hemsy de Gainza (1995), debido a que cuenta con un repertorio gestual mucho más amplio.

\section{LOS JUEGOS DE MANOS Y SU CONTEXTUALIZACIÓN}

\section{1. ¿Qué son los juegos de manos o Amarillo?}

Cuando se les pregunta a las -y los- participantes por los juegos de manos en Chile y por canciones de dar palmas en España (cançons de picar en catalán, en Catalunya), todas saben a qué nos referimos. A pesar de ello, en su práctica diaria nunca usan ese concepto, tan abstracto y general. Las niñas y los niños se refieren a su práctica por el nombre de la canción 
específica, es decir, por el título de la canción-juego. A pesar de ello, las comprenden como un tipo de actividad específica y diferente del resto. Hablaremos de sus participantes en femenino, porque es el género mayoritario de estas canciones.

“-¿Conocéis los juegos de manos? - ¡Sí! La de Michael Jackson, Amarillo, Las vocales...” (participante de once años, España).

Aunque las participantes conciben claramente como canciones separadas a muchas de ellas, en el análisis de los textos pudimos observar la dificultad que existe para separar muchas de las canciones por sus títulos, ya que partes importantes de sus textos aparecían en diferentes canciones. Es lo que se denomina intertextualidad, y que Julia Kristeva (1997) explica de la siguiente forma: "Todo texto se construye como un mosaico de citas, todo texto es absorción y transformación de otro texto”. Asimismo, Pelegrín (1992: 184), en su investigación, destaca esta cuestión recurrente y extendida en el mundo musical infantil en el que la memoria, los juegos de prenda, la habilidad en juegos de manos y acertijos, el recitado de trozos de comedias, el acopio de un repertorio del romancero y cancionero antiguo y el contemporáneo a su tiempo, los cuentecillos de ingenio y chiste se entremezclan de forma ingeniosa al paso del tiempo.

A continuación se muestra un ejemplo de intertextualidad con cuatro juegos de manos recogidos en el trabajo de campo. Calle veinticuatro, recogida en ambos países, comparte una parte de la canción con Caperucita Roja, escuchada en Chile, y con Barbie. Esta última fue escuchada en Cataluña (Cardedeu), aunque una niña venezolana de doce años, en Chile, comentó haber escuchado y jugado en su país con una parecida llamada Don Pepe (ver Tabla 1).

\section{TABLA 1: INTERTEXTUALIDAD EN CUATRO JUEGOS DE MANOS RECOPILADOS EN EL TRABAJO DE CAMPO}

\begin{tabular}{|c|c|c|c|}
\hline Calle veinticuatro & Caperucita Roja & Barbie & Don Pepe \\
\hline \begin{tabular}{|c|} 
En la calle lle \\
veinticuatro tro \\
ha habido do do \\
un asesinato to: \\
Una vieja ja \\
mató un gato to \\
con la punta ta \\
del zapato to. \\
Pobre vieja, pobre gato, \\
pobre punta del zapato.
\end{tabular} & $\begin{array}{c}\text { Tin tin. ¿Quién es? } \\
\text { Soy caperucita roja, } \\
\text { una niña muy celosa. } \\
\text { En la calle veinticuatro, } \\
\text { una vieja pisa un gato. } \\
\text { Pobre vieja, pobre gato, } \\
\text { pobre punta del zapato. } \\
(\ldots)\end{array}$ & 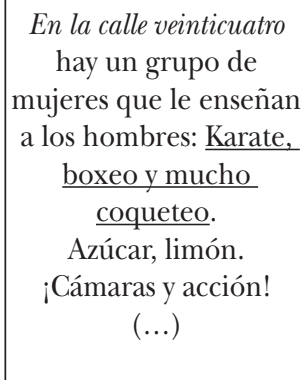 & $\begin{array}{l}\text { Don Pepe el jefe de la } \\
\text { one, two, three. } \\
\text { A nosotras las mujeres } \\
\text { nos encanta así: } \\
\text { Karate, Boxeo y mucho } \\
\text { Onequeteo. } \\
\text { One, two, three. }\end{array}$ \\
\hline
\end{tabular}

Fuente: Elaboración propia.

Más allá de la denominación de cada juego de manos, las participantes no parecen concebirlos como una preferencia de juego para el recreo. En las seis escuelas observadas, ante la pregunta “¿qué juegos hacéis durante el recreo?”, ninguna participante nos ha respondido rápidamente "juegos de manos". De hecho, era necesario un pequeño momento de reflexión para que apareciera en algunas de las respuestas. En la escuela de La Serena se preguntó a un grupo completo de $4^{\circ}$ básico $\left(4^{\circ}\right.$ de elemental) por juegos que hicieran en la escuela. Después de enumerar muchísimos juegos, nadie había nombrado los juegos de manos hasta que se les preguntó directamente por la actividad en cuestión. Entonces, 
todos ellos y todas ellas levantaron la mano. Y todos, incluida la profesora, eran y habían sido participantes u observadores de esos juegos.

Asimismo, ellas mismas refieren los juegos de manos como un pasatiempo cuando no hay nada mejor que hacer. Es decir, no es una preferencia de juego de recreo sino una solución al "tiempo muerto", para "pasar el rato" y superar el "aburrimiento". Cuando se observa su emergencia en el recreo, se confirma lo que ellas mismas responden de manera homogénea ante la pregunta de cómo se empieza a jugar:

"Empieza en alguna parte, da igual dónde, y otras se añaden o empiezan a hacerlo también. No se define tanto por el lugar...sino más bien por la espera. Es por el aburrimiento" (participante de trece años, Santiago de Chile).

\section{2. ¿Cómo se origina y se desarrolla este repertorio?}

En los grupos de discusión se observa la aparición del concepto de juego de manos en los años sesenta y setenta, tanto en Chile como en España. Si bien es cierto que, previo a estas décadas, los juegos de manos también aparecen mencionados por los informantes, hay de nuevo coincidencia en los dos contextos en no concebirlos como una actividad específica. En otras palabras, antes de los años antedichos esta actividad se pensaba de forma conjunta con el resto de los juegos cantados, como son las rondas o el saltar a la cuerda.

En España, participantes nacidos entre los años veinte y treinta recordaban haber jugado con las palmas mientras cantaban, pero señalaban que cualquiera de ellas podía ser también para saltar a la cuerda o para bailar en corro. Algunas de las canciones recogidas fueron Anton Calavaina, Baixant de la font del gat, Chocolate amarillo, El señor don gato, En el fondo del mar, Soy la reina de los mares, Joan petit quan balla, Cocherito leréy Desde pequeñita.

En Chile, por el contrario, las canciones de ronda y de cuerda no aparecían durante estos años en forma de juegos de manos. En cambio, es importante destacar Las palmitas como predecesor de los juegos de manos, aunque los participantes no lo relacionan con los "de hoy en día”, de acuerdo con lo recogido en los grupos de discusión. Este tipo de juego fue informado por participantes nacidas entre 1938 y 1943, no era cantado y únicamente se acompañaba de gesto. La finalidad también era hacerlas cuanto más rápido mejor, si bien su función pareciera ser la de calentarse en invierno:

"Nosotras hacíamos las palmitas para calentarnos las manos cuando hacía frío" (participante nacida en 1943 en Chile).

En este sentido, es interesante resaltar de nuevo que, ya sea por la música o el texto, parte del repertorio que forma parte en la actualidad de los juegos de palmas existía de algún modo con anterioridad a esta actividad.

Otro dato importante es que, tanto en Chile como en España, descubrimos una correlación entre la desaparición de las rondas de forma espontánea en el juego popular infantil en escuelas y en plazas, y el crecimiento de los juegos de manos en esos mismos espacios hacia los años setenta.

En España, los cantos tradicionales como las rondas, con gran presencia como juego popular durante la primera mitad del siglo XX, fueron perdiendo su espacio. En nuestro trabajo de campo se recuerdan las rondas como forma popular en las escuelas y plazas españolas hasta personas nacidas en los años cincuenta, es decir, hasta los años sesenta y principios de los setenta. A partir de 1965 y 1970 aparece esta correlación que mencionábamos entre la desaparición de cantos tradicionales en el juego popular infantil, como las rondas, con el crecimiento de nuevos juegos cantados: saltar a la comba o los juegos de manos son los principales ejemplos de ello. Según la opinión de los entrevistados, los juegos 
de manos tuvieron su auge en los años noventa, pero según lo observado en el trabajo de campo, actualmente siguen siendo el canto-juego más utilizado popularmente en las áreas de juego (recreos, pasillos o extraescolares).

En Chile esa correlación también se da. Aparece una disminución de rondas (La ronda de San Miguel o Alicia va en el coche son ejemplos de las últimas rondas a nivel popular que llegaron hasta los años setenta) al mismo tiempo que otras actividades lúdico-musicales, como los juegos de manos, se expanden en las zonas de recreo, sobre todo en escuelas. Como consecuencia del contexto político, a principios de los setenta la escuela mixta (que ya existía en algunas escuelas) y la educación pública se expanden a nivel nacional. Debido a que los juegos de manos se transmiten de forma horizontal -de participante a participante-, esta situación que facilitaba el acceso de niños y niñas a la escuela puede haber favorecido su expansión. Posteriormente, durante la dictadura militar, los juegos de manos fueron expandiéndose hasta llegar a su máxima difusión en los años noventa, de igual forma que en España. Y actualmente, en pleno siglo XXI, tanto en España como en Chile los juegos de manos siguen siendo conocidos por casi todos los niños y niñas, participantes o no, desde los cinco o seis años. La mayoría reconocen haberlos visto o haber jugado con ellos. Su expansión a nivel internacional es evidente, y existe una gran cantidad de juegos de manos que aparecen en los dos contextos, con las variantes propias de la transmisión oral. Algunos ejemplos de ello serían En la trampa del león y Barbie.

\section{Trampa del león}

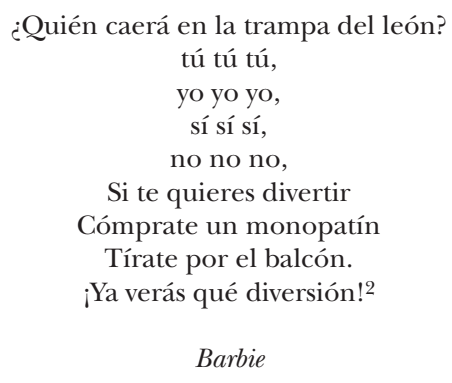

En la calle veinticuatro hay un grupo de mujeres que le enseñan a los hombres karate, boxeo y mucho coqueteo. Azúcar, limón, cámaras y acción. Abiertas, cerradas y yo me quedo así3.

\section{3. ¿Dónde se juega en los contextos español y chileno?}

En las observaciones de esta investigación, realizadas entre octubre de 2018 y octubre de 2019 tanto en Chile como en España, sigue siendo la escuela el espacio más habitual de actuación. La mayoría de las niñas asegura hacer juegos de manos durante la hora de recreo, aunque fueron difíciles de observar durante esta investigación. Las zonas más usadas son:

2 Recogida en España en las dos escuelas donde se llevó a cabo el trabajo de campo por participantes de seis años la primera parte de la canción (¿Quién...No, no, no) y por participantes de ocho años toda entera.

3 Recogida en España en la escuela de Cardedeu por niñas de nueve años. 
pasillos, bancos y alrededores, infraestructuras de juego (castillos...), porche, escaleras y zonas periféricas. De todos modos, no solamente ocurre en la escuela. Según distintos informantes, también se da en las casas, zonas lúdicas de fuera de la escuela, momentos de espera (transporte, colas...). A diferencia de trabajos de campo previos (Riera 2013), en estos momentos aparece de forma evidente la plataforma YouTube como medio y nuevo espacio virtual de aprendizaje y de transmisión de estos.

\section{4. ¿Cuál es la experiencia individual y colectiva?}

La actividad de los juegos de manos envuelve su ejecución y la estructura propia del juego, como son las narrativas, melodía y gesto. En todas sus partes, incluida su ejecución, se observa la importancia de esta actividad en la construcción del género. Cuando se pregunta a los informantes acerca del tipo de participante, todos coinciden en que es un juego de niñas, aunque haya algunos niños que también jueguen.

En el trabajo de campo se recoge la misma información. Se trata de un juego feminizado en el que algunas veces aparecen niños participantes. En una escuela en particular, en Santiago de Chile, se observó niños que conocían bien dos canciones, Frutillita y Chocolate, y que jugaban separadamente de las niñas. En la escuela de La Serena, los niños y las niñas conocían muchas canciones que sabían ejecutar. A pesar de ser una actividad hecha más por niñas que por niños, lo remarcable en esta escuela es que los niños no la concebían como un juego de niñas. En España también se observó participación masculina, básicamente algunos pocos niños que se juntaban con las niñas. En general, estos son conceptualizados como mejores amigos, distintos a aquellos "otros" que jugaban a otro tipo de juegos, como el fútbol.

"Yo jugaba sí. (...) y eso me daba lata porque se reían de nosotros cuando nos juntábamos a jugar, porque supuestamente es un juego de niñas. Nosotros somos mejores amigos desde hace mucho tiempo y llevamos muchísimo tiempo desde que nos molestan" (chico de catorce años, Santiago de Chile).

Incluso se recogió la opinión de algunos niños mofándose de los juegos de manos por ser de niñas:

"Estas canciones son tontas, porque hacen $<<$ ñi-ñi-ñi $>>$ con las manos (hace movimientos supuestamente femeninos)" (niño de diez años, Cardedeu, España).

"Era más de niñas. (...) No recuerdo haber jugado. (...) Estos juegos de manos me dan asco, como que me dan rabia... no me gustan. Son de niñitas" (chico de trece años, Santiago de Chile).

En definitiva, las niñas acostumbran a ser las protagonistas de la actividad. La situación de predominio que ejercen las niñas supone tener un rol más alto a nivel jerárquico: ellas mandan y deciden quién juega y quién no. En la práctica, se traduce en rechazar otros participantes por no poder seguir el juego a la misma velocidad, en ayudarse unas a otras para que puedan aprenderlas, y en evitar jugar con niños si estos no son "buenos amigos". En el trabajo de campo aparecen discursos del tipo "son demasiado difíciles para los niños, que no tienen memoria ni habilidad con las manos", "nosotras tenemos habilidades en las manos y ellos en los pies". Esta última frase indica cómo se identifican con el juego y cómo esta actividad resulta clave para la construcción del género femenino en el espacio de recreo (frente a otros juegos masculinizados, como es el fútbol).

En las narrativas de las canciones también se observan categorías masculinas y femeninas en los roles que pueden seguir los personajes. En algunos casos los masculinos son agresivos, autoritarios, activos, maltratadores o asesinos. Los femeninos pueden ser bonitas 
(sexis, culpables, víctimas, débiles, pasivas) o bien brujas/viejas/locas (activas, rabiosas y malas). En otros, los textos subvierten estos tópicos y aparecen mujeres que son agresivas, princesas valientes o brujas/viejas buenas y hombres culpables, débiles o pasivos.

\section{LA RELACIÓN ENTRE MÚSICA, TEXTO Y COREOGRAFÍA}

\subsection{La combinación de gestos no es aleatoria}

Durante el trabajo de campo pudimos vislumbrar que los diferentes gestos usados por las niñas (y algunos niños participantes) no se combinaban de forma aleatoria. Existía una relación entre algunos gestos, creando patrones que las participantes conocían bien. De la misma manera que diferenciaban entre las canciones de los juegos de manos por el texto, en el trabajo de campo nos dimos cuenta de que también diferenciaban canciones que se hacían con unos patrones gestuales respecto de otras que se hacían con otros patrones. En otras palabras, existen unos patrones coreográficos establecidos, sea con más o menos variantes:

"Este juego es así, no sé por qué, pero se hace con este movimiento. Con el otro no sería correcto" (niña de ocho años, Santiago de Chile).

Las participantes clasifican los juegos de manos según la combinación de gestos, que las hacen diferenciarse o agruparse entre sí. Esta característica no sucede con el texto ni con la melodía:

“Tía, yo conozco otra con estos gestos ¿Se la muestro?” (niña de diez años, Santiago de Chile).

A pesar de ello, no se cuestionan la diferencia de coreografía, reproducen y modifican según lo que han aprendido basándose en la práctica y no en la reflexión:

"Ella me enseñó así la canción de Amarillo. Yo nunca la he visto con estos gestos que me dices" (niña de ocho años, Cardedeu).

La finalidad de los juegos de manos, como hemos visto en la introducción, recae en la complejidad y velocidad de ejecución; es decir, cuanto más compleja, más diversión:

"Se hace con estos gestos porque es más divertido. Con el otro es muy fácil (...) hay algunas más con estos, pero yo no las conozco bien" (niña de nueve años, Cardedeu).

Aun así, atribuirse el conocimiento de un juego de manos tiene que pasar por la melodía, pero sobre todo por el texto:

"Yo no me sé la canción. Aunque sí sé hacer así, mira (ejecuta la combinación de gestos de la canción Frutillita)" (niño de ocho años, Santiago de Chile).

La complejidad de los juegos de manos se basa en la relación entre el gesto, el ritmo en el texto y la melodía que le acompaña. En España, y específicamente en Cataluña, encontramos que actualmente los infantes de cinco años toman como preferencia a Dan dan dero, Colorín Colorado y Don Macarrón Chistero para iniciarse en esta actividad. En Chile, específicamente en Santiago de Chile, aparece Chocolate y Mariposa como primeras elecciones a la edad de cinco años, todas ellas con coreografías simples. La mayoría de las veces la combinación gestual es lo primero que se aprende: 
"Se sabe los gestos, pero la pobre no sabe cantarla aún" (profesora hablando acerca de niña de cinco años en Santiago de Chile).

En el proceso de imitación y reproducción encontramos niñas que observan a ejecutantes, incluyéndose en el juego cantando la canción alrededor de las otras. Según ellas y las participantes, se sabe la canción, pero no los gestos. Por tanto, se observa que mientras texto y melodía no pueden concebirse por separado; la parte gestual, sí:

"Yo me sé la canción, pero no me salen los gestos" (niña de ocho años, Cardedeu).

\subsection{Tipos de coreografía y su relación con texto y melodía}

Estos patrones gestuales, a los que hemos llamado coreografías, se ayudan del uso de la repetición cíclica hasta al final de la canción. Como desarrollaremos a continuación, hemos definido cinco patrones principales: coreografía cruzada, coreografía de base, coreografía estándar, coreografía de balanceo y coreografías específicas. Los nombres de cada combinación gestual han sido creados por los autores de este artículo.

La combinación y el uso de los gestos pueden -o no- tener relación con el texto y melodía. Debido a su carácter popular y dinámico, algunos de los gestos de una coreografía pueden aparecer con variantes. Por ejemplo, pueden existir repeticiones de los gestos o combinaciones de ellos de manera distinta entre las canciones que hacen uso de una misma coreografía. En algunas ocasiones surge una misma canción de palmas con otra combinación gestual, es decir, con otro tipo de coreografía. En el trabajo de campo observamos esta diferencia con la canción Punto y coma entre participantes de contextos dispares (por ejemplo, una niña venezolana en una escuela pública chilena que aseguraba conocer la canción, pero con otros gestos distintos, cambiando de coreografía estándar a coreografía de balanceo). También se observó que a veces se cambiaba la coreografía a propósito, porque había alguna participante incapaz de seguirla con la original:

"Con mi hermana pequeña la hago, pero con ella la hago así [coreografía de base] porque así [coreografía estándar] no me sigue” (niña de diez años, Santiago de Chile).

A continuación presentamos las diferentes coreografías: la coreografía cruzada, la coreografía de base, la coreografía estándar, la coreografía de balanceo y finalmente las coreografías específicas (ver Tabla 2). Las tonalidades correspondientes se han elegido a base de la semejanza con las voces infantiles registradas.

\section{TABLA 2: CLASIFICACIÓN DE LAS DISTINTAS COREOGRAFÍAS QUE SE MUESTRAN EN ESTE ARTÍCULO}

COREOGRAFÍA CRUZADA
(Inicios de la década de 1930 en Chile y España)




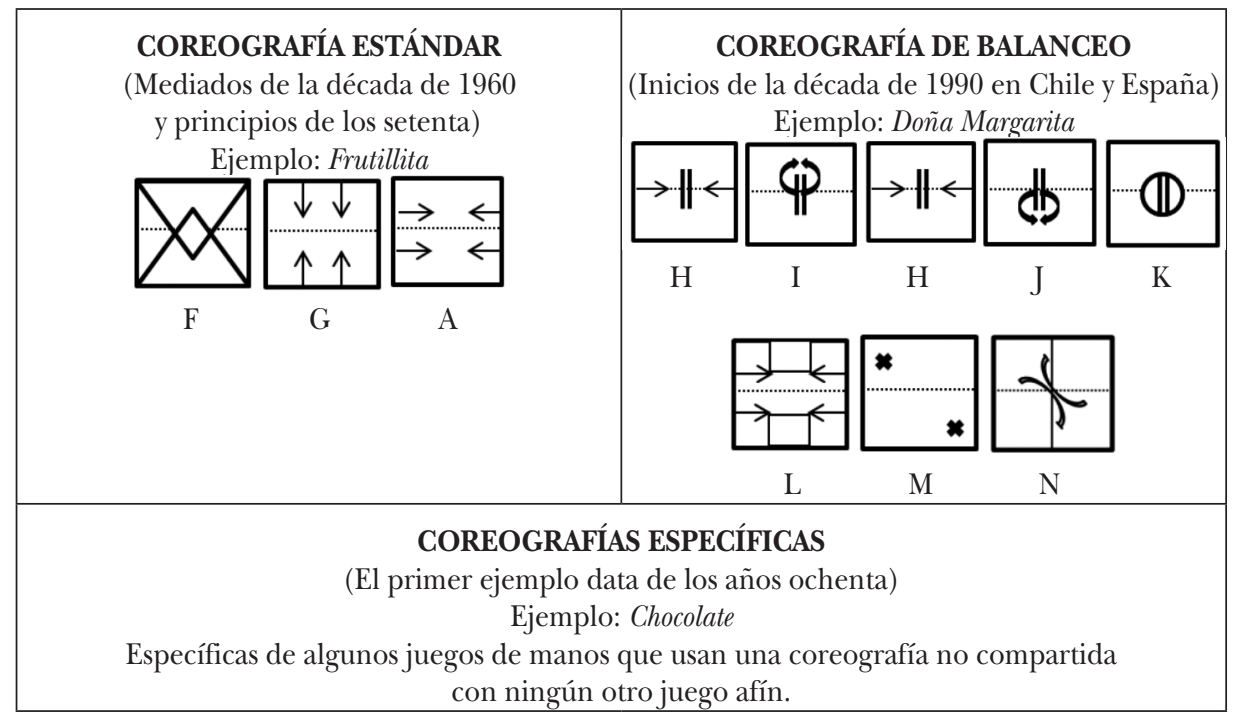

Fuente: Elaboración propia.

\subsubsection{Coreografía cruzada}

Figura 1

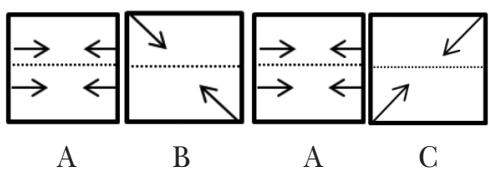

El gesto A: dar una palmada con las propias manos. Puede aparecer en juegos de manos grupales o enfrentadas. En el caso que sea en grupal se dan las palmadas, una con la participante de la derecha y la otra con la participante de la izquierda simultáneamente (ver Figura 1).

El gesto B: la mano derecha de la jugadora da una palmada con la mano derecha de la otra jugadora en el caso de estar enfrentadas, cruzando los brazos en el centro. En algunas ocasiones se da de manera grupal, entonces la mano derecha de la jugadora da una palmada con la mano izquierda de la jugadora que tiene a su izquierda (ver Figura 1).

El gesto C: la mano izquierda de la jugadora da una palmada con la mano izquierda de la otra jugadora en el caso de estar enfrentadas, cruzando los brazos en el centro. En algunas ocasiones se da de manera grupal, entonces la mano derecha de la jugadora da una palmada con la mano derecha de la jugadora que tiene a su derecha (ver Figura 1).

Algunas veces se acompaña de otros gestos.

Figura 2

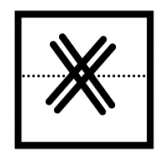

$\mathrm{O}$ 
El gesto O: es uno de esos casos. Las dos manos con los dedos entrelazados giran hacia afuera para chocar las palmas contra las del compañero, en idéntica posición. Solo se da en posición de enfrentadas (ver Figura 2).

\section{Contextualización}

Este tipo de combinación ya aparece en participantes de los años treinta en Chile y España en canciones de ronda. En Chile, Las palmitas, ya presentadas con anterioridad, usaban la coreografía cruzada pero sin canto. Podrían ser un predecesor de los juegos de manos, teniendo en cuenta que la primera coreografía que aparece históricamente en estos cantos de dar palmas la cruzada. Como ya hemos avanzado, los informantes de Las palmitas son personas nacidas entre los años treinta y cuarenta, de regiones del Norte, Centro y Sur del país. Durante los años 1965 y 1970 empezó a usarse específicamente para algunos juegos de manos, es decir, gesto y canto a la vez.

En la actualidad también existen juegos de manos sin canto con coreografía cruzada que se acompañan a veces de algunas palabras que guían el movimiento. Un ejemplo es el juego de manos One, one two, one two three... donde las figuras retóricas son la enumeración y concatenación en inglés que acompañan -o se acompañan-, de la suma de los gestos A y $\mathrm{B} / \mathrm{C}$ del número concatenado que se explicita en la letra de forma recitada. Como todas las coreografías que le siguen, se repite de forma cíclica a lo largo de la canción. En este caso, crea además un efecto de encadenamiento de los gestos que ayuda a darle movimiento y continuidad. Actualmente, también es una de las coreografías elegidas cuando uno de los participantes no puede hacer una coreografía más compleja. Algunos ejemplos: Las vocales, Pepsicola, Calipo, Se murió Candela.

"La vamos a hacer así, porque si no a ella no le sale. ¿vale?” (Cardedeu, niñas de diez, y siete años).

\section{Su su su (Pepsicola)}

Pop. infantil iberoamericana
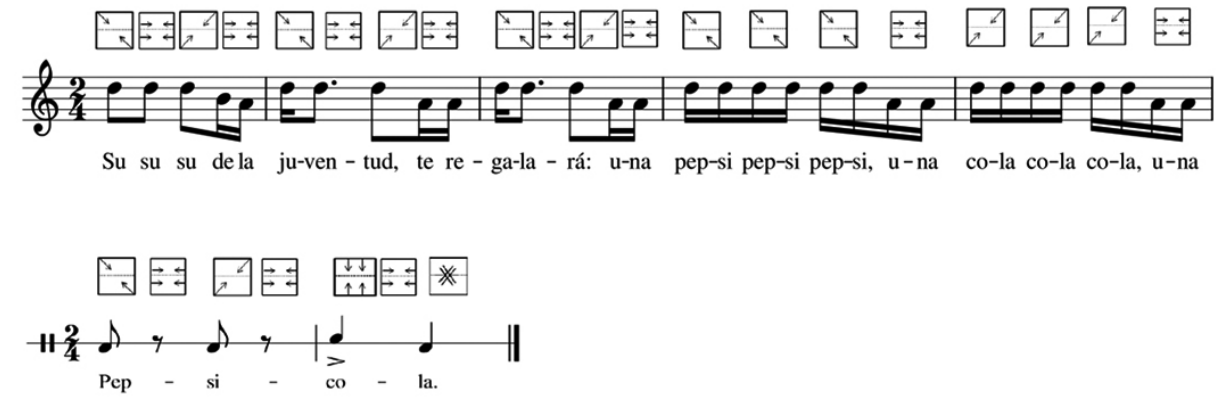

Figura 3: Su su su (Pepsicola). Fuente: Transcripción propia.

El presente ejemplo (ver Figura 3) se basa en un juego de manos de dos personas enfrentadas. Su su su se basa en dos sonoridades a distancia de cuarta justa, siendo su centro tonal alrededor de re. La reduplicación de $<<\mathrm{su}\rangle>$ al inicio de la canción viene acompañada de la misma nota, asegurando el centro tonal en forma de introducción. Esta palabra 
repetida sin sentido facilita la entrada de la combinación gestual concatenada y favorece su continuación. La palabra $<<j u v e n t u d ~>>$ marca acento en la primera sílaba $<<j u>>$ que viene introducida con el gesto A en las notas si y la, y que ataca desde abajo al re (gesto B) de forma anacrúsica. Este efecto también sucede con la palabra $<<$ regalará $>>$ donde la anacrusa, de nuevo a distancia de cuarta, marca acento en la segunda sílaba de la palabra. El gesto acompaña a la anacrusa de la misma manera que en la palabra $<<$ juventud $>>$. La frase $<<$ te regalará $>$ invita al juego esperando una respuesta. La repetición de $<<$ Pepsi $>>$ con gesto $\mathrm{B}$ y $<<$ cola $>>$ con gesto $\mathrm{C}$, manteniendo el centro tonal en re y los gestos repetidos, separados por una anacrusa a distancia de cuarta, ayudan a aprender la palabra por partes. En la coreografía cruzada, el gesto B y C a veces se repite para intensificar la intención del texto. Además, la polisemia de la palabra $<<$ cola $>>$, recordando a un animal, divierte a las participantes tal y como observamos en el trabajo de campo acompañándolo de una sonrisa. La anacrusa, de nuevo a distancia de cuarta, introduce el final de la canción: la palabra $<<$ pepsicola $>>$. Esta se recita con una pequeña modificación al final que exige concentración en el gesto y en la palabra. El acento de la sílaba tónica $\langle$ co $\rangle>$ se remarca con el primer gesto distinto al resto de la canción y un sonido un tanto más agudo, en coherencia con el centro tonal usado hasta ahora.

\subsubsection{Coreografía de base}

Figura 4

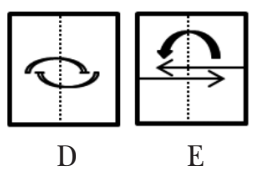

El gesto D: en el caso en que sea grupal, la mano derecha de la jugadora sostiene la mano izquierda de la jugadora de la derecha, mientras que su mano izquierda se apoya en la palma de la mano derecha de la jugadora de la izquierda. En el caso en que sea juego a dos, la mano derecha de la jugadora sostiene la mano izquierda de la otra jugadora. Enfrentadas o en círculo (ver Figura 4).

El gesto E: se combina con el gesto D. Cuando le llega el turno, la jugadora levanta la mano derecha y la arquea por delante del cuerpo hacia su izquierda, golpeando la mano derecha abierta y mirando hacia el cielo de la compañera. Acto seguido la mano derecha de la jugadora vuelve a descansar en la mano izquierda de la compañera creando de nuevo el gesto D (ver Figura 4).

\section{Contextualización}

Esta coreografía, al igual que la anterior, es de las más antiguas en los dos contextos iberoamericanos. Parece ser que su origen está relacionado con los juegos de ronda. En general se juega en grupos grandes y la finalidad suele estar relacionada con la construcción de vínculo social y el conocimiento de los participantes y de sus relaciones sociales. También se usa como coreografía sencilla si uno de los participantes no se sabe la coreografía de una canción. Aparece encadenamiento de los gestos como vimos con la anterior y, por su sencillez, ayuda a poder centrarse en el texto y melodía. Este tipo de coreografía en círculo cerrado se acostumbra a hacer con el grupo de amigas y es un facilitador del desarrollo 
del vínculo de amistad. En muchos casos las letras hablan de aspectos vinculados con sacar información del grupo. Por este motivo, en algunas ocasiones hay más participación masculina en ellas que en otras. Un ejemplo del tipo de información se puede observar en esta canción recogida en España (Cardedeu):

Debajo de la mesa

Debajo de la mesa

hay una carta

es de tu novio

¿Cómo se llama?

¿Te has besado alguna vez con él?

$¿$ ¿Te has duchado alguna vez con él?

(...)

No hubo registro de esta coreografía en Chile, ni en las escuelas ni en los grupos de discusión. Aun así, algunas participantes admitían conocerla. En España aparece en los años setenta con la canción El conejo de la suerte y se mantiene la coreografía hasta la actualidad. Algunos ejemplos: El conejo de la suerte, Don macarrón chistero, Debajo de la mesa.

\section{Don Macarrón}

Pop. infantil, España (Barcelona)
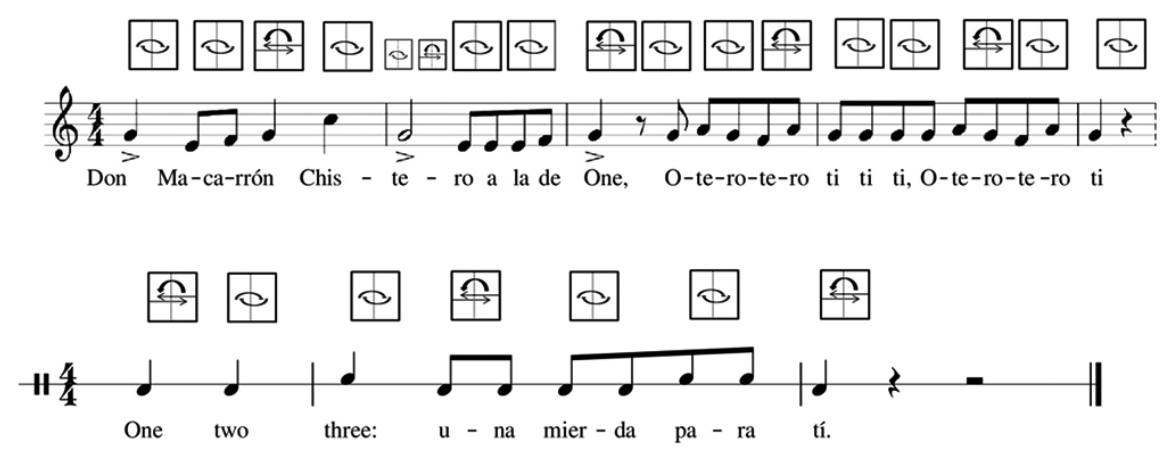

Figura 5: Don Macarrón. Fuente: Transcripción propia.

El canto melódico se mueve alrededor del centro tonal de sol (ver Figura 5). La canción empieza usando un motivo rítmico-melódico de una canción popular catalana usada para saltar a cuerda. Aunque actualmente no la observamos en los recreos, participantes nacidas en los noventa y que también habían jugado a Don Macarrón, recordaban haber jugado a saltar a cuerda con ella:

Si la barqueta es tomba

Si la barqueta es tomba nena no tinguis por. Alça la corda enlaire i canta una cançó. 


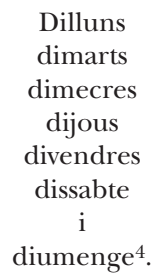

El ejemplo de coreografía de base de la partitura se ha realizado con la hipótesis de ser un grupo de tres participantes. Esta coreografía es diferente del resto porque los gestos dependen del número de personas que van a jugar. En el caso en que fueran dos, se intercalarían los gestos (DE-DE-DE) pero cuando son más, como en la muestra, las participantes deben esperar hasta que les llegue el turno para hacer el gesto E. En el ejemplo, la participante no empieza haciendo el gesto $\mathrm{E}$ hasta la sílaba $<<$ rrón $\gg>$ siendo otra participante la que lo inicia. A pesar de que la experiencia individual de ser protagonista del gesto $\mathrm{E}$ solo se dará en un turno, el acento en relación con los tiempos del canto se da cada vez, ya que cada participante se ocupa de un turno y así hasta que le vuelve a llegar. Que haya un tiempo más fuerte que otro depende solo de la fuerza con la que se genere el gesto E. El hecho de que en cada tiempo se refuerce y se acentúe con un gesto $\mathrm{E}$ de alguna de las participantes hace que, a pesar de mostrarse en un compás 4/4, las participantes la piensen por cada tiempo por separado e incluso manteniendo la expectativa a que le llegue su turno. En la partitura, a modo de ejemplo, es probable que la participante además de escuchar acento en todos los tiempos, el que ella ejecuta (cada tres tiempos) sea más sentido que el resto, lo que permite una experiencia individual distinta para cada una de las jugadoras. La finalidad del juego es apartar la mano cuando la participante que le toca hacer el gesto E en la última palabra $<<\mathrm{ti}>>$ vaya a aplaudirle. En otras palabras, la mano de la receptora mira hacia el cielo y debe ser capaz de apartarla antes de que la protagonista del gesto E, se la aplauda. Como depende del número de jugadoras y de quién empieza, las participantes nunca saben a quién le va a tocar y están todas en tensión esperando el momento.

\subsubsection{Coreografía estándar}

Figura 6

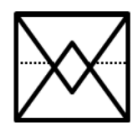

$\mathrm{F}$

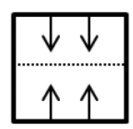

G

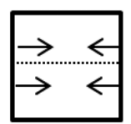

A

El gesto F: la mano derecha, con la palma hacia abajo, desciende y golpea la izquierda del compañero (palma hacia arriba) y, simultáneamente, la mano izquierda con la palma hacia arriba, sube y golpea la derecha del compañero (palma hacia abajo). En el caso que sea en círculo se dan las palmadas, una con la participante de la derecha y la otra con la participante de la izquierda simultáneamente (ver Figura 6).

4 Si la barquita se dobla, niña no tengas miedo, tira la cuerda al aire y canta una canción. 
El gesto G: las dos palmas paralelas y horizontales chocan con las del compañero. En el caso que sea grupal, una palmada choca con la palmada de la participante de la derecha y la otra con la participante de la izquierda simultáneamente (ver Figura 6).

El gesto A: dar una palmada con las propias manos. Puede aparecer en juegos de manos grupales o enfrentadas. En el caso que sea en grupal se dan las palmadas, una con la participante de la derecha y la otra con la participante de la izquierda simultáneamente (ver Figura 6). Este gesto, de igual modo que el gesto B y C comunes en la coreografía cruzada, también está relacionado con algunos recursos retóricos del texto que se intensifican con los gestos, como es la reduplicación (ver Figura 7):

Figura 7

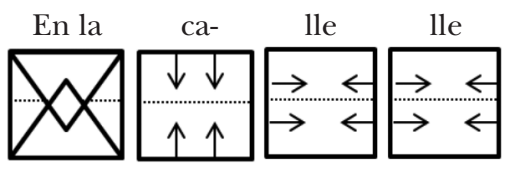

\section{Contextualización}

Tuvo sus inicios hacia los años 1965 y 1970 en Chile y en España. Aparece cuando la idea de "juego de manos" se especifica y se diferencia del resto. Es una combinación de gestos más compleja que las anteriores. La finalidad es hacerlo cuanto más rápido mejor. Se trata de una coreografía en la que a menudo aparecen intercalados muchos movimientos descriptivos que acompañan al texto aportando significado y vinculando la narrativa con la coreografía (ver Figuras 9 y 10). Esta intervención de gestos descriptivos podría ocurrir, porque se trata de una combinación de tres gestos que se repite de forma cíclica pero no existe la concatenación entre ellos. De ese modo, el gesto descriptivo se daría después del gesto $\mathrm{C}$ y de nuevo empezaríamos por el A, presentándose de nuevo de manera natural. Se trata de la coreografía más utilizada desde entonces. Algunos ejemplos: A la one two three, Don Federico, La lechera, Calle veinticuatro, Barbie, Michael Jackson, En el castillo de Frankenstein, Caperucita Roja, Frutillita.

Figura 8

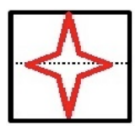

Gesto descriptivo: en este artículo usamos este símbolo para cualquier gesto descriptivo que aparezca representado en los ejemplos (ver Figura 8). 


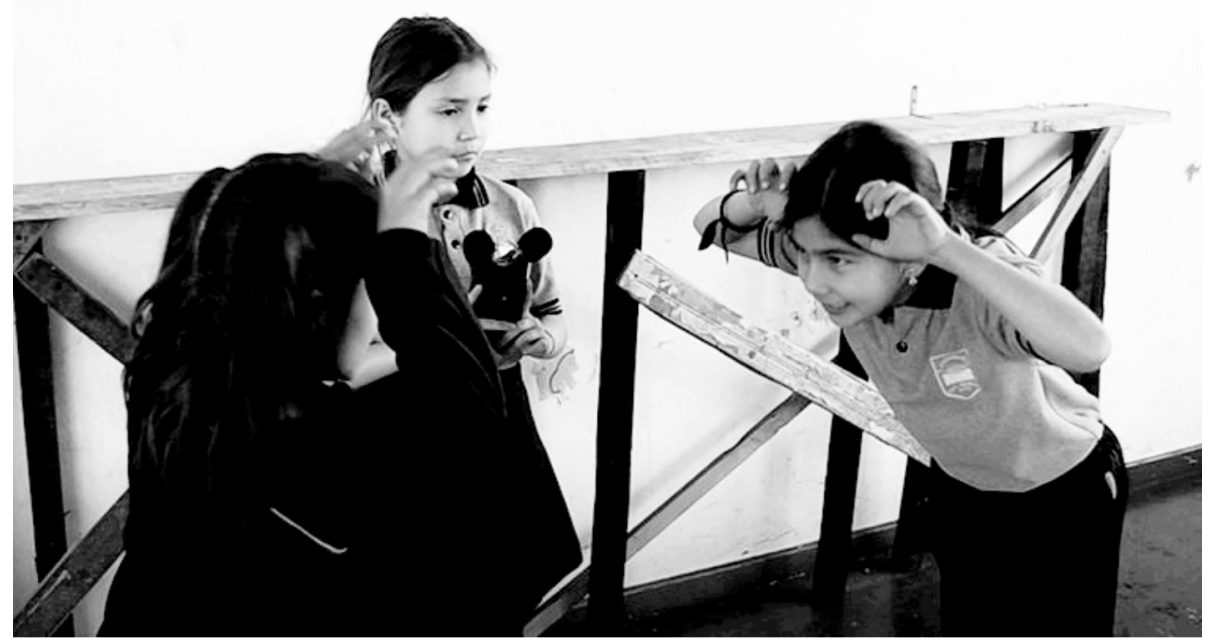

Figura 9: Gesto descriptivo de la palabra animal del juego de manos Punto y coma, en la escuela Fernando Alessandri Rodríguez en Santiago de Chile. Fotografía extraída de un video grabado en trabajo de campo (3 de septiembre de 2019).

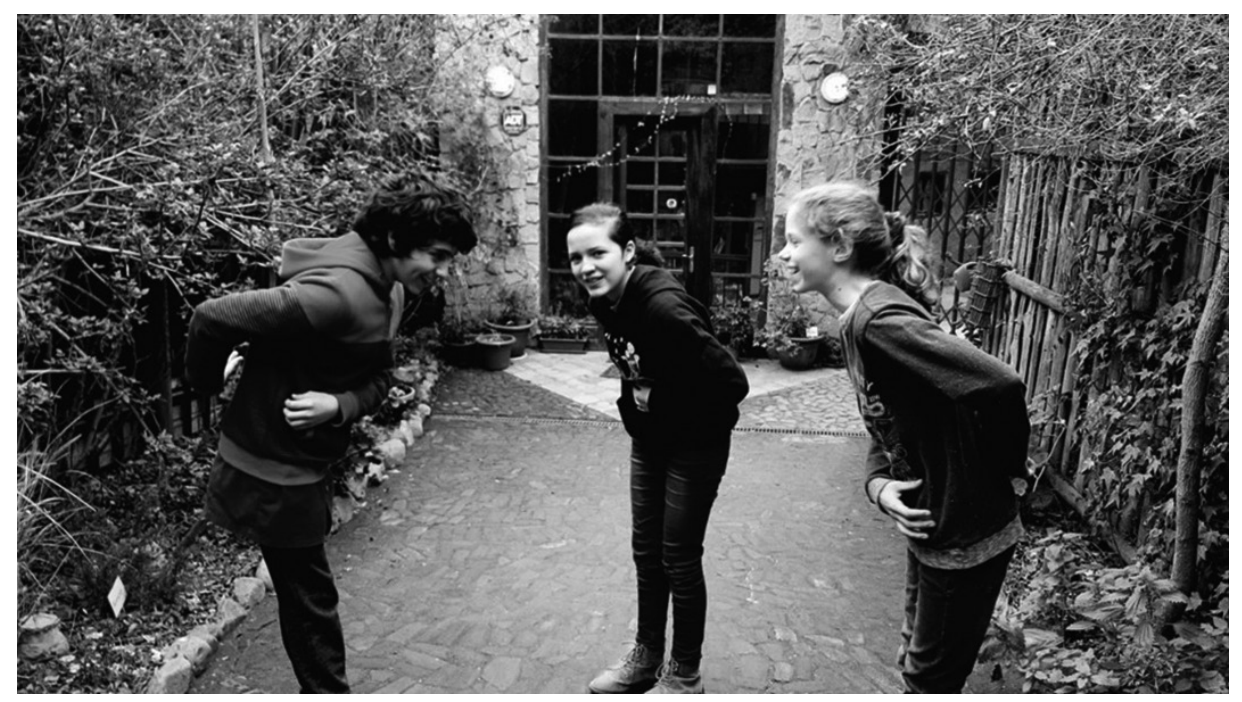

Figura 10: Gesto descriptivo de la palabra caballero del juego de manos A la One, two, three, en la escuela Maison les enfants en Santiago de Chile. Fotografía de trabajo de campo, 31 de julio de 2019. Niños de trece años mostrando una de las últimas canciones con las que habían jugado hasta el año anterior. 


\section{Frutillita}

Pop. infantil, Chile (Santiago)
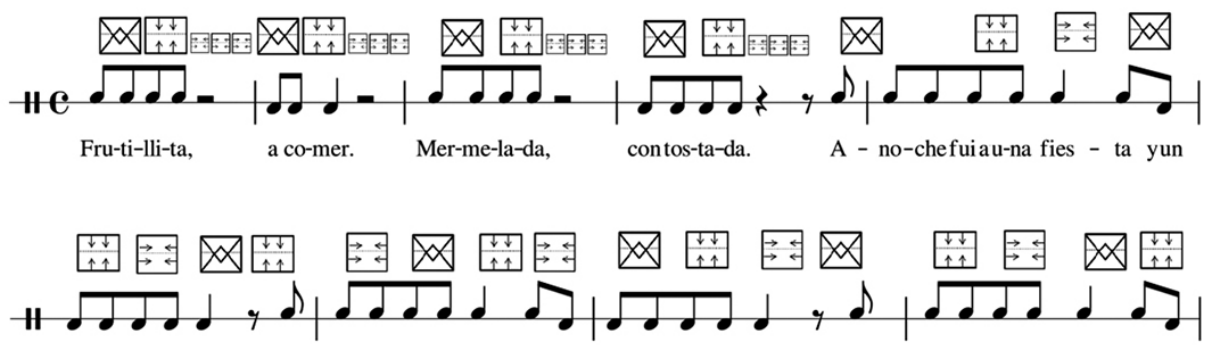

chi-co me be-só. Le diu-na ca-che-ta - da y to-do sea-ca-bó. Miher- ma-na-tu-vounhi - jo la

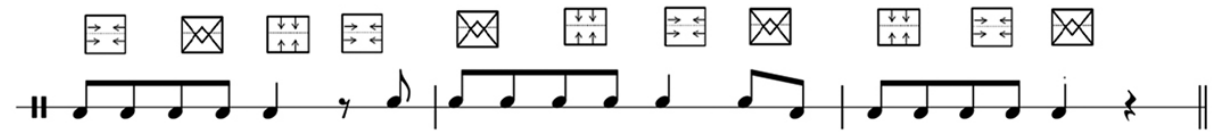

lo-cat lo ma-tó. Lo hi - zo pi - ca - di - lloy des - pués se lo co-mió.

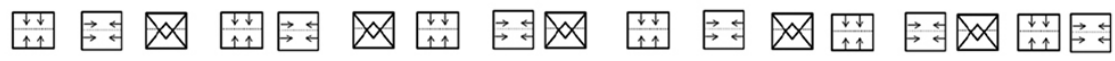
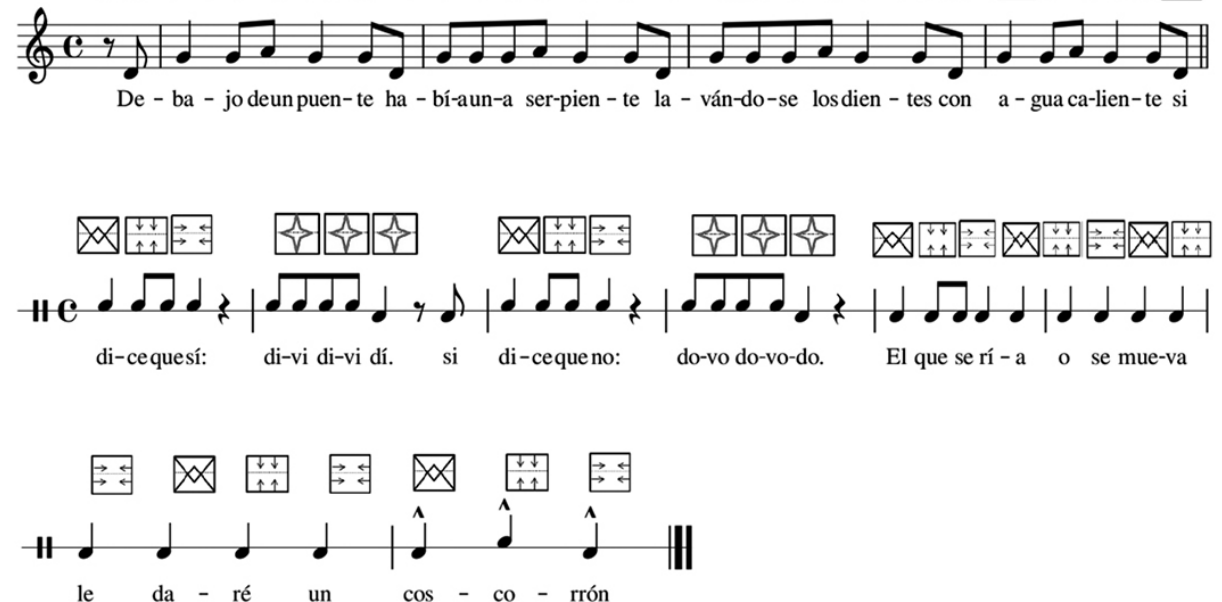

Figura 11: Frutillita. Fuente: Transcripción propia.

La canción tiene una parte recitada y una melódica (ver Figura 11). La palabra $<<$ cachetada $>>$ es una apropiación cultural habitual en Chile. La primera estrofa $<<$ Frutillita a comer, mermelada con tostada $>>$ se divide en dos versos. $<<$ Frutillita $>>$ y $<<$ mermelada $>>$ se recitan en forma de pregunta con un tono más agudo in crescendo y $<<$ a comer $>>\mathrm{y}<<$ con tostada $\gg$ se recitan en forma de respuesta con un tono más grave in decrescendo. En algunas observaciones hechas a niños participantes, estos dos versos aparecen casi rapeados acompañados de una postura chulesca del cuerpo. Entre estas partes existe un silencio 
rellenado con la reiteración del gesto A por tres veces. La finalización de la primera estrofa clausura la introducción de la canción. Justo después, con la siguiente estrofa se inicia la combinación cíclica de la coreografía FGA-FGA-FGA... hasta el final de la canción. El gesto A es el tiempo fuerte gestual y no tiene por qué coincidir con las sílabas tónicas del texto ni con características melódicas. Las dos siguientes estrofas contienen cuatro versos, los que se basan en cuatro tiempos, separados por un silencio e iniciados con anacrusa otorgando movimiento. Como se puede observar, el gesto A no siempre coincide con el primer tiempo de cada verso, lo cual crea contrapunto entre el gesto y el texto, y aumenta la dificultad del juego. Una vez finalizadas estas dos estrofas, se inicia una melodía que proviene de una canción popular infantil escuchada en los grupos de discusión en España a participantes que pasaron su infancia hacia los años setenta y que dice así:

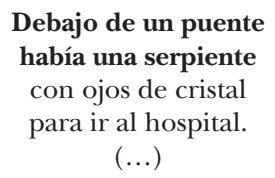

La tonada del juego de manos mantiene la base del patrón rítmico melódico (en nuestra partitura re-sol-sol-la-sol-sol) que se da en los dos primeros versos de la canción popular infantil $<<$ Debajo de un puente, había una serpiente $>>$ y los repite, siendo distintos al canto tradicional, en los dos segundos versos $<<$ lavándose los dientes, con agua caliente $>$, adaptándose a las palabras del texto.

La anacrusa a nivel de cuarta inicia el canto, la combinación de gestos vincula las anteriores estrofas con esta canción y siguiendo la no concordancia entre gesto y texto. Una vez finalizada empieza la conclusión de la canción. Los versos $<<$ si dice que sí (...) >> $\mathrm{y}<<$ si dice que no $(\ldots)>>$ se acompañan de un ciclo de coreografía estándar cada verso. Recitado y a modo de pregunta se presenta la figura retórica de antítesis (sí, frente al no) esperando una respuesta $<<$ dividividí $>>$ y $<<$ dovodovodó $>>$. La respuesta se da con un gesto descriptivo moviendo los brazos hacia la derecha en el caso del sí y hacia la izquierda en el caso del no, rompiendo con el ciclo coreográfico y reforzando los opuestos. Como vimos anteriormente, la coreografía estándar se usa habitualmente para intercalar movimiento descriptivo, reiniciando siempre la coreografía desde el gesto de inicio F. En esta versión se sigue de una última frase larga de final caprichoso e inesperado $<<$ el que se ría o se mueva le daré un coscorrón $>>$. Se mantiene el tono grave hasta llegar a la parte interesante a nivel semántico: la palabra aguda $<<$ coscorrón $>>$, que se destaca con acento las dos primeras sílabas, resaltando la segunda en tono agudo y cayendo en tono grave en la última silaba. Toda la frase se acompaña del ciclo gestual en contratiempo que, sorprendentemente, acaba el tiempo fuerte gestual junto con el tiempo fuerte silábico de la última palabra aguda $<<$ rrón $>>$.

Tal y como sucede en Frutillita respecto de la canción popular infantil Debajo de un puente, existen versiones que para mantener la rima hacen uso de la intertextualidad. En muchos casos, se recrea un absurdo que las participantes destacan como divertido e invita al juego:

“i(...) Y es divertido que la serpiente se lave los dientes porque no tiene manos! Debe usar la cola...así -gesticula describiendo la acción mientras las otras niñas también se ríen-" (niña de ocho años, Santiago de Chile).

De hecho, en España existe una versión aún más antigua (de principios de siglo XX) de esta canción popular infantil, probablemente una ronda, y que recoge María Jesús Martín Escobar (2001: 422) en su investigación: 


\title{
(...) \\ Me llevaron a Belén; de Belén, a la fuente, donde había un penitente con las llaves de oro para abrir el coro, con las llaves de metal, para abrir el hospital.
}

Esta misma canción sigue así:

$$
\begin{gathered}
(\ldots) \\
\text { Levántate, Candela, } \\
\text { y enciende la vela, } \\
\text { y mira a ver quién anda } \\
\text { por la carretera. } \\
(\ldots)
\end{gathered}
$$

En otra canción de coreografía de balanceo (expuesta más adelante) recogida en el trabajo de campo en Chile, aunque de una participante de origen venezolano, encontramos de nuevo intertextualidad con esta otra estrofa de la canción popular infantil inicial:

\author{
Se murió Candela \\ Se murió Candela \\ por lo linda que era. \\ Derramó su sangre \\ por la carretera. \\ $(\ldots)$
}

\subsubsection{Coreografía de balanceo}

Figura 12

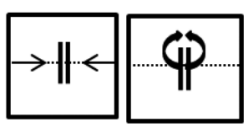

$\mathrm{H}$

I

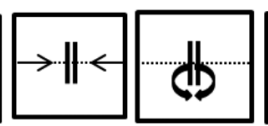

$\mathrm{H}$

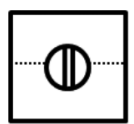

$\mathrm{K}$

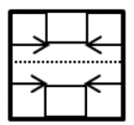

$\mathrm{L}$

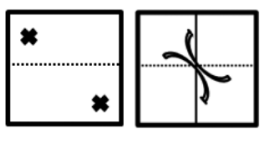

$\mathrm{M}$

$\mathrm{N}$

Esta coreografía solo se puede llevar a cabo entre dos participantes, por tanto, no existe la posibilidad a hacerla de manera grupal.

El gesto H: la palma izquierda (dedos apuntando hacia adelante) se junta con la palma izquierda del compañero. La palma derecha toca el dorso de la mano izquierda de la compañera, creando como un pequeño núcleo de las cuatro manos intercaladas en el centro de las dos participantes (ver Figura 12).

El gesto I: manteniendo el "conjunto" que conforman las respectivas palmas izquierdas unidas, se da una palmada con la derecha a la derecha de la compañera por arriba. A veces se sustituye la palmada por una sacudida de manos (ver Figura 12).

El gesto J: manteniendo el "conjunto" que conforman las respectivas palmas izquierdas unidas, se da una palmada con la derecha a la derecha de la compañera por abajo (ver Figura 12). 
El gesto K: manteniendo el "conjunto" que conforman las respectivas palmas izquierdas unidas, se cogen de las respectivas manos derechas por abajo y las llevan verticalmente hacia arriba mientras se deshace "el conjunto" de las palmas izquierdas, y se vuelve a construir por debajo de las manos derechas. Finalmente, se deja la mano derecha libre y se mantienen las manos izquierdas cogidas en forma de saludo formal en el centro de los cuerpos de las participantes, a nivel del ombligo (ver Figura 12).

El gesto L: mientras se mantienen las manos izquierdas como juntas en el centro, se dan una palmada en alguna parte de su cuerpo: nalga o pecho (ver Figura 12).

El gesto M: mientras se mantienen las manos izquierdas como juntas en el centro, chasquean los dedos de la mano derecha por encima del hombro (ver Figura 12).

El gesto N: las manos derechas dan una palmada por arriba de sus cabezas, y devuelven el movimiento dando de nuevo una palmada esta vez con el dorso de las manos. Este gesto se da mientras se interpreta el final del gesto K (ver Figura 12).

\section{Contextualización}

Esta coreografía tiene sus inicios en los años noventa, y es la segunda más utilizada en la actualidad, según el estudio realizado del que se sirve este artículo. Es una coreografía más compleja que exige movimientos hacia arriba, hacia abajo, hacia los lados con el cuerpo, y coordinación con la compañera de juego. Se trata de una coreografía a dos, que repite su patrón en forma cíclica hasta el final. Por su presentación encadenada y entrelazada de los gestos, no permite introducir gestos descriptivos. Se ha observado algún juego en coreografía de balanceo que se ha cambiado a coreografía estándar añadiendo gestos

\section{Doña Margarita}

Pop. infantil, España (Barcelona)
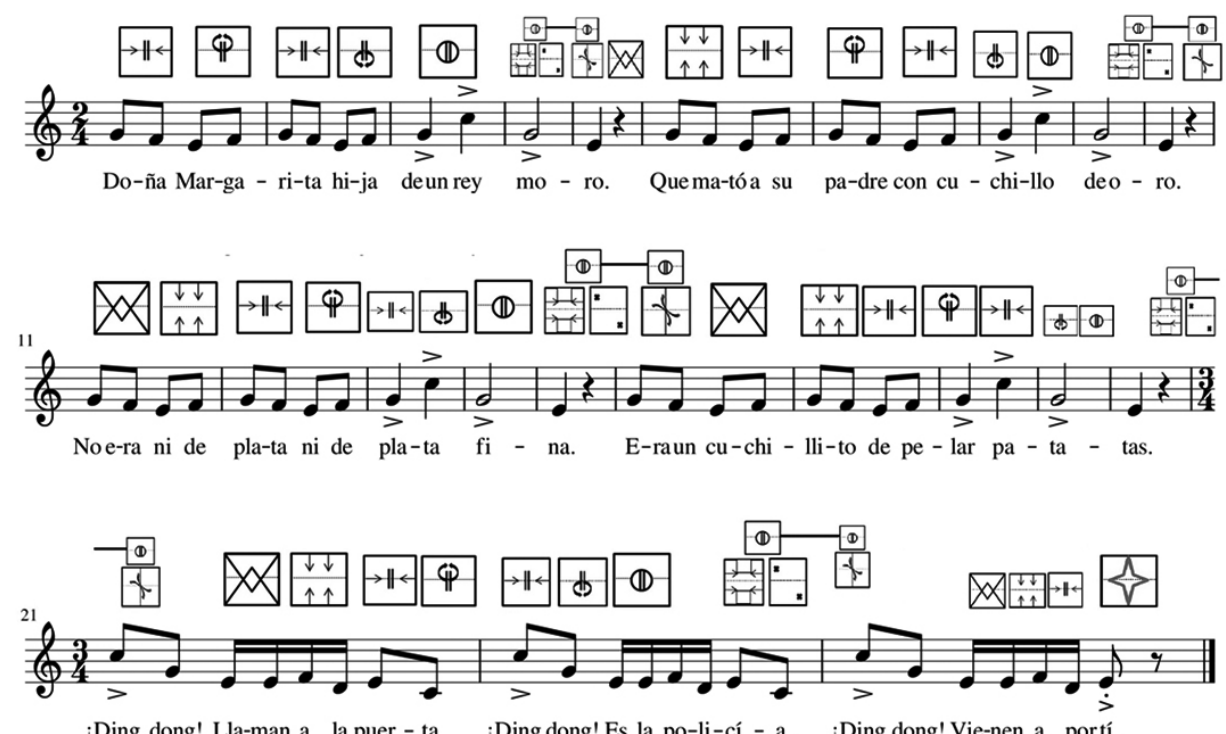

Figura 13: Doña Margarita. Fuente: Transcripción propia. 
descriptivos (por ejemplo, Punto y coma). En algunos casos, se usa solo los gestos con la combinación siguiente: H-I-H-J (ejemplo: Homero, La muerte, etc.), la cual es muy utilizada en el caso de los participantes varones. En otros casos, como en Amarillo, la combinación aparece toda entera. En la canción Doña Margarita se observó la mezcla entre la coreografía de balanceo y la coreografía estándar, aunque en el trabajo de campo se pudo observar que los participantes la consideran dentro de la coreografía de balanceo. Generalmente, la finalidad está en la complejidad de los movimientos: cuanto más rápido, mejor. Algunos ejemplos: Pikachu, Homero, La muerte, Al revés, Doña Margarita y Amarillo.

La canción empieza con la coreografía completa de balanceo (HIHJKLMN) y se sirve del gesto FG, es decir, combinado con coreografía estándar para finalizar el ciclo. El gesto $\mathrm{H}$ recuerda al gesto A pero en vez de ser una palmada individual de las participantes, se unen las cuatro manos en el centro. Las niñas tienen muy interiorizada la coreografía estándar por ser la más usada de todas ellas. Es posible que los gestos FG, entre el $\mathrm{N}$ y el $\mathrm{H}$, faciliten el inicio de la coreografía de balanceo posicionando las manos en gesto $\mathrm{H}$ y poder seguir rápidamente.

Melódicamente hablando, existen dos partes diferenciadas por dos centros tonales distintos. Por lo general, el centro tonal es alrededor de sol, hasta llegar al cambio de compás en el número veintiuno, donde empieza a moverse alrededor de do como centro tonal. De igual modo que sucedía con Don Macarrón, la canción empieza con un motivo rítmico-melódico de una canción popular catalana de saltar a cuerda llamada $A$ la barrejada. Conocida por algunas participantes nacidas en los años ochenta, época en la que parece originarse Doña Margarita según los grupos de discusión, no ha sido observado como juego de saltar la cuerda en el trabajo de campo de la investigación en la que se basa este artículo.

\section{A la barrejada}

A la barrejada, qui no entra, para.

A la barrejada, qui no surt, ha perdut.

En esta canción de saltar la cuerda los participantes deben entrar y salir fluidamente de la cuerda en movimiento, pues la canción no puede parar. Del mismo modo, en los juegos de manos es fundamental poder seguir de principio a fin, tanto que, en algunos casos, puede eliminarse la coreografía compleja (en este caso la coreografía de balanceo) por otra menos compleja (coreografía cruzada), para poder llegar hasta el final.

El patrón HIHJKLMN FG se repite cinco veces y finaliza con un $\mathrm{H}$ sumado a un gesto descriptivo. Los patrones gestuales no coinciden con las frases lírico-melódicas en ningún caso, pero a pesar de ello cada uno de los ciclos reviste un nuevo verso, iniciándose una vez que este ya empezó. Existe un momento clave en la canción con interesantes aportaciones. Llegando al compás 20, después de una estrofa de cuatro versos, la canción contextualiza a las participantes en una historia narrada (una chica ha matado a su padre) acompañada de una compleja combinación gestual concatenada a la que, llegados a este punto, ya se han habituado a ejecutar, se han compenetrado hasta tal punto que pueden proceder al compás 21 con un cambio importante a nivel rítmico-melódico y textual. A veces los gestos que acompañan al compás 20 se dan a más velocidad, haciendo entrar un gesto más de lo habitual en un tiempo, para empezar con el gesto N en el compás 21.

Otras veces, las participantes crean un silencio de un tiempo antes de empezar el compás 21. Lo que vemos en ese punto, textualmente, es que la protagonista asesina pasará a ser la propia participante del juego, lo que moviliza el sujeto hasta el mismo yo ejecutor. Esta es perseguida por la policía que llama tres veces a la puerta. Este cambio se da a gran velocidad, propia de quien quiere escapar de la institución y se siente atrapado. El significado narrativo se refuerza con un cambio de compás marcado a tres tiempos y reforzado 
por un verso por cada compás. Los tres versos empiezan con el centro tonal agudo y su quinta en descendiente, simulando la llamada del timbre de casa; los dos primeros versos del final (“¡Ding dong! Llaman a la puerta / ¡Ding dong! Es la policía”) acaban con una caída melódica que exalta aún más la sorpresa del timbre. La tercera y última frase es exactamente igual melódica y rítmicamente hablando que las dos anteriores, manteniéndose fiel hasta la última corchea, que acaba con la nota que le pertenecía por posición (la tercera del centro tonal) dejando la historia y la melodía en suspenso, sin un final conclusivo. La fidelidad que observamos en la melodía no parece ser el caso del gesto, donde de nuevo encontramos tres gestos que acostumbrarían a ocupar un tiempo y medio, insertados en un solo tiempo en forma de tresillo rítmico sobre cuatro semicorcheas. En el trabajo de campo, se pudo observar que las participantes esperaban con concentración ese final ya que existe además un objetivo común entre ellas. Acabar la canción con el gesto FGN, basado en la coreografía estándar (vienen a por...) y el gesto descriptivo (ti), el más importante de todos, pues se trata de señalar la compañera como culpable de asesinato, antes que lo haga la otra. Aunque en la práctica casi siempre se hace a la vez y no se discute por ello.

Doña Margarita es una versión de juego de manos que parece provenir de un romance español recogido por Oreste Plath (1946: 216) titulado Santa Catalina que se usaba para cantar en rueda, girando las niñas alrededor de una que quedaba en el centro. En ella, el padre mata a su hija cristiana al encontrarla en oración.

$$
\begin{aligned}
& \text { La Santa Catalina, } \\
& \text { para bon, bon, bon } \\
& \text { era hija de un rey } \\
& \text { haya, haya, haya } \\
& \text { Un día en la plegaria, } \\
& \text { para bon, bon, bon, } \\
& \text { su padre la encontró } \\
& \text { haya, haya, haya }
\end{aligned}
$$

Su padre era pagano, para bon, bon, bon su madre no lo era, haya, haya, haya.

Yo mato a Catalina para bon, bon, bon, porque no me obedece, haya, haya, haya.

Traedme mi cuchillo, para bon, bon, bon, mi hacha y mi puñal, haya, haya, haya.

Traen al rey sus armas Para bon, bon, bon, y mata a Catalina haya, haya, haya.

Los ángeles bajaron para bon, bon, bon, cantándole la gloria, haya, haya, haya. 
En la canción de palmas, recogida como Santa Teresita en participantes de grupos de discusión en España nacidas en los años sesenta, y como Doña Margarita en participantes actuales del trabajo de campo en España, aparece la subversión de la historia. En este caso es la protagonista la que mata a su padre. El cambio a primera persona del personaje en la última estrofa facilita la apropiación de identidad del personaje y su historia por parte de la participante. Ante la pregunta ¿por qué crees que mata a su padre? Una respuesta habitual eran tales como:

“(...) Porque algo malo debió hacer él. No lo matará porque sî” (niña de once años, Cardedeu).

La canción facilita la apropiación de la identidad de la niña como Doña Margarita, como hemos visto. Es probable que gracias a ello puedan responder con esas reflexiones, en las que se interpreta que ella es una víctima y él es la causa de su mala actuación ("algo malo debió hacer él").

\subsubsection{Coreografías especificas}

Basadas en gestos que, combinados entre sí, solo aparecen en una canción de palmas particular. Cada una de ellas, pues, tiene un patrón específico gestual que no aparece en ningún otro juego de manos. Algunos ejemplos: Doctor Jano, Mariposa y Chocolate.

\section{Contextualización}

El primer juego de manos con coreografía específica recogida en esta investigación fue con participantes nacidos en la década de 1970, es decir, que pasaron su infancia en los ochenta, en España.

\section{Chocolate}

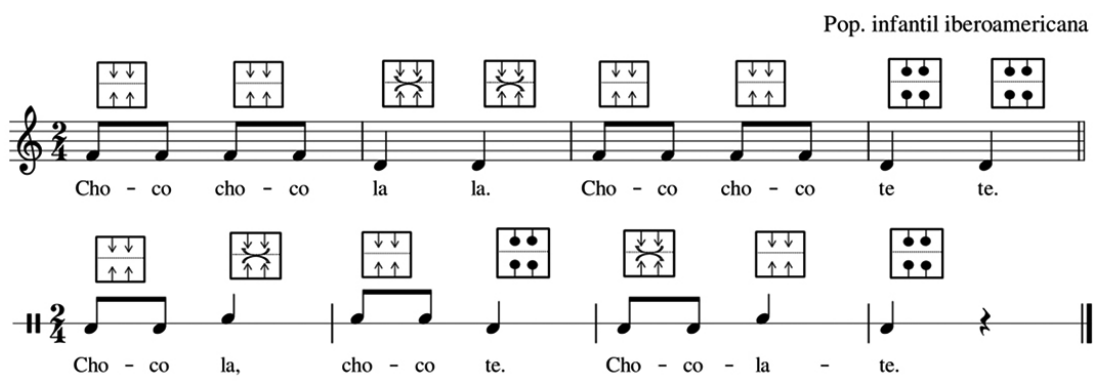

Figura 14: Chocolate. Fuente: Transcripción propia.

En este caso aparecen los siguientes gestos:

Figura 15

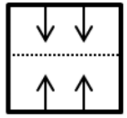

G

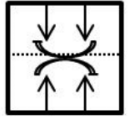

O

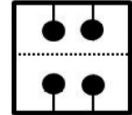

P 
Gesto G: chocan las palmas de la mano frontalmente (ver Figura 15).

Gesto O: chocan los dorsos de la mano frontalmente (ver Figura 15).

Gesto P: chocan los puños frontalmente (ver Figura 15).

Por su sencillez en la letra y en los gestos, parece ser una de las canciones con las que se inician los jugadores a los juegos de manos. A nivel melódico, existe una primera parte melódica, basada en un intervalo de tercera menor, típica de la música popular infantil, y otra segunda recitativa. A diferencia de los casos anteriores, donde no existe coincidencia entre los versos y los gestos, en Chocolate la relación gesto, melodía y sílaba se vuelve finalidad en sí misma. Observamos que existe un gesto para el morfema $<<$ choco $>>$ acompañado de la nota musical más aguda. Se sigue de la sílaba $\langle<l a>>$, con un gesto distinto al anterior, acompañado de una nota musical por debajo de la que acompaña al morfema. De nuevo se repite el gesto-nota y el morfema $<<$ choco $>>$ y se sigue de la sílaba $<<$ te $>>$. Esta sílaba, que ocupa una posición distinta a $<<\mathrm{la}>>$ en la palabra va acompañada de la misma nota musical que $<<$ la $>>$, aunque el gesto es distinto. Esto podría recordar que $<<$ choco $>>$ es la parte importante de la palabra y las otras dos sílabas quedan por debajo de la jerarquía al mismo nivel, aunque son distintas como demuestra la diferencia de gesto y la pronunciación misma. Una vez presentado el morfema con cada una de las sílabas que conforman la palabra (choco la / choco te), termina presentando la palabra entera $<<$ choco-la-te $>>$, combinación que no había aparecido hasta entonces y, por tanto, no ha sido aprendida con antelación. Este aspecto hace que se complique la ejecución de los tres gestos seguidos con la palabra completa. Por ello, habitualmente los participantes ralentizan el tiempo asegurando su posición.

\section{CONCLUSIÓN Y PROSPECTIVA}

Este artículo da respuesta a los objetivos que se presentaban inicialmente: a) contextualizar la actividad musical que son los juegos de manos iberoamericanos a nivel histórico y sincrónico; b) categorizar los gestos según las combinaciones que aparecen; y, por último, c) analizar la relación entre la melodía, el texto y gesto.

Hasta el momento ningún artículo previo había definido y sistematizado las diferentes tipologías o patrones coreográficos. A base del trabajo de campo se han podido definir cinco: la coreografía cruzada (la más antigua en su contexto histórico), la coreografía de base (la menos utilizada en número de canciones, pero la que tiene mayor función de desarrollo de vínculo social), la coreografía estándar (la más utilizada en mayor número de canciones), la coreografía de balanceo (la más moderna y compleja de todas) y, finalmente, las coreografías específicas (solo usadas por un tipo de juego de manos).

Los recursos coreográficos, textuales y rítmico-melódicos, a pesar de recurrentes introducciones novedosas, se mueven alrededor de ciertas lógicas que hemos descrito en este artículo. Los tres atributos nunca van por separado, aunque en su proceso de aprendizaje puedan aislarse en algún caso. Los juegos de manos, como actividad que es, no pueden ser entendidos sin estos tres atributos unidos y toda la actividad que contiene. De hecho, su especialidad como concepto empieza por la coreografía y debe pasar por el texto y la melodía, como se ha demostrado. Está llena de relaciones vinculantes entre sus partes, y estas a su vez con la ejecución musical de las participantes, así como con aquellos participantes pasivos y no participantes.

Las coreografías no modifican la estructura de la canción, pero la enriquecen. En algunos casos emana el contrapunto por estar organizados en grupos de tiempos distintos (por ejemplo: una secuencia ternaria en una canción de compás cuaternario). El tiempo 
fuerte del ritmo gestual no tiene por qué coincidir con los acentos de la métrica de la melodía. Podría ser que las niñas a veces organizaran la parte gestual independientemente de las palabras y la melodía, así como apuntaba Curtis (2004), pero la complejidad aumenta cuando observamos puntos de unión entre el final del ciclo o acento gestual, junto con el final del verso o acento silábico, como se ha mostrado en los resultados. Así, pues, los gestos están combinados y no aparecen de forma aleatoria. Acompañan a los recursos retóricos, a la semántica y a la melodía, reforzándola en muchos casos.

Como se ha mostrado, los juegos de manos son un claro ejemplo de repertorio popular infantil en que las niñas y los niños son productores y reproductores, es decir, creadores musicales de sus propias prácticas. Su aparición se da espontánea en el tiempo, probablemente porque, a pesar de poder contextualizar su origen en puntos históricos claros, su emergencia siempre es en presente y nunca se cuestiona su aparición ni por las participantes ni por ningún centro educativo que las institucionalice en las escuelas.

En cuanto a la contextualización de los juegos de manos, tanto en Chile como en España, se empezaron a desarrollar especialmente en los años sesenta y setenta, al mismo tiempo en que disminuyen algunos cantos o juegos populares, como las rondas. Otro juego cantado, el salto a la cuerda, ya existía previamente junto con las rondas y se mantiene junto con los juegos de manos hasta la actualidad. Como se ha observado, existe una influencia clara entre los diferentes juegos cantados.

En España, esta época coincide con la apertura del régimen español y las nuevas influencias de los mass media (televisión, cine), el turismo y los primeros movimientos feministas que llevaron a liberar a la mujer de su rol meramente en el espacio privado. En Chile, la época en que surgen coincide con los gobiernos de Eduardo Frei Montalva y de Salvador Allende Gossens, un momento marcado por la expansión de la educación pública y mixta a nivel nacional.

Según la imagen percibida por los informantes de esta investigación, los juegos de manos están actualmente en declive, aunque los resultados en el trabajo de campo no lo muestran en ningún caso. De hecho, los juegos de manos están por todas partes, desde contextos de nivel socioeconómico alto hasta contextos de nivel socioeconómico bajo; sea en escuelas particulares como subvencionadas o públicas.

El aburrimiento parece ser la causa principal de su uso y quizás por ello, en general, las participantes no las conciben en sí como un juego de recreo; de hecho, este pensamiento explicaría que pueda ser encontrado en pasillos en la escuela entre horas, en esperas tales como en transporte o en restaurantes, o bien en la hora de recreo en sí misma. En la escuela, los espacios más usados son los pasillos, alrededor de los bancos y zonas más periféricas.

Basándonos en Lada (2007), el texto narrativo oral literario no permanece siempre igual en su forma, porque no existe una versión definitiva de un relato, sino tantas versiones como participantes de este. Lo mismo sucede con los juegos de manos: al deber su naturaleza a la transmisión oral, no son creaciones nuevas. Quedan en manos del momento, siempre desde la actualidad, desde lo popular. Y de la misma manera progresiva y disimulada, se desvanecen. La modificación de los textos, coreografías y melodías son recogidas de cualquier fuente, por lo general de otros juegos de manos, o bien de antiguos romances, de personajes de televisión, de canciones famosas e incluso de anuncios comerciales. Esta condición evoca a la aparición de la intertextualidad dando a conocer varias versiones de una misma canción.

La construcción como individuo femenino o masculino, tanto a nivel narrativo como a nivel del uso del espacio y la ejecución de la actividad, desde una óptica del discurso de género, es palpable a lo largo del estudio. Esto es gracias al entrelazado complejo en el que la participante requiere del resto para su óptima realización, demostrando enlaces de amistad, desarrollando el vínculo social entre compañeros de juego, creando límites con aquellos que 
no juegan y con los cuales no se identifican, y dejando entrar a aquellos que son "buenos amigos" capaces de comprender la necesidad de la mujer de liberarse del rol débil y pasivo establecido o formar parte activamente de su palabra, mediante los juegos de manos.

Llegados a este punto, consideramos que sería necesario seguir investigando acerca de los juegos de manos en habla hispana. A nivel antropológico, un análisis exhaustivo actual de cómo los sujetos participantes viven, sienten y desarrollan la actividad aportaría una perspectiva complementaria que actualmente no existe. En paralelo, sería importante hacer un análisis de contenido temático de los juegos de manos actuales desde una perspectiva de género interseccional. Por otro lado, sería interesante conectar este tipo de estudio con otras formas de estudio de la cultura popular infantil; por ejemplo, por medio de la etnografía virtual, analizando qué está sucediendo con los juegos de manos en las redes sociales.

\section{BIBLIOGRAFÍA}

ACKerley, JANice

2007 "The Subversive World of New Sealand Children's Playground Rhymes", Journal of Folklore Research, XLIV/2, pp. 205-225. DOI: 10.2307/40206951

ArLeo, ANDY

2001 "The Saga of Susie: The Dynamics of an International Handclapping Game", In Play Today in the Primary School Playground. Julia C. Bishop y Mavis Curtis (editores). Buckingham: National Centre for English Cultural Tradition - University of Sheffield, pp. 115-132.

Barrett, Margaret

2003 "Meme engineers: Children as producers of musical culture", International Journal of Early Years Education, XI/3, pp. 195-212. DOI: 10.1080/0966976032000147325

BAUER, LAURIE Y WiNIFRED BAUER

2007 "Playing with Tradition", Journal of Folklore Research, XLIV/2, pp. 185-203. DOI: $10.2307 / 40206950$

Bhana, Deevia; Thokozani Nzimakwe y Phumzile Nzimakwe

2011 "Gender in the Early Years: Boys and Girls in an African Working Class Primary School", International Journal of Educational Development, XXXI/5, pp. 443-448. DOI: 10.1016/j. ijedudev.2010.09.001

BlatchFord, Peter

1998 "The State of Play in Schools", Child Psychology and Psychiatry Review, III/2, pp. 58-67. DOI: $10.1017 / \mathrm{S} 1360641798001488$

Burn, ANDREW

2014 "Children's Playground Games in the New Media Age", Children's Games in the New Media Age: Childlore, Media and the Playground. Chris Richards y Andrew Burn (editores). Londres: Routledge, pp. 1-30.

Casals, Albert y Joanna Riera

2015 "We Are Gunslinging Girls: Gender and Place in Playground Clapping Games", Atlantis: Critical Studies in Gender, Culture E⿱ Social Justice, XXXVII/1, pp. 54-69.

Curtis, Mavis

2004 "A Sailor went to sea: theme and variations", Folk Music Journal, XVIII/4, pp. 421-437. DOI: $10.2307 / 4522717$

DÍAZ, JOAQUíN

1971 Palabras ocultas en la canción folklórica. Madrid: Taurus.

Fernández Poncela, Anna M.

2005 Canción infantil: discurso y mensajes. Barcelona: Anthropos. 
Ferré, GABriel

1993 “Cançons infantils folklòriques actuals: notes descriptives i assaig d'anàlisi”, Revista d'etnologia de Catalunya, 3, pp. 50-65.

GAUNT, KYRA

2006 The games black girls play: learning the ropes from doublé-dutch to hip-hop. Nueva York: NYU Press.

Gómez, JUAN

2004 "La poética del pop: los recursos retóricos en las letras del pop español”, Anales de Literatura Española, XVII/3, pp. 49-72. doi: 10.14198/ALEUA.2004.17.03.

González, Darío Alberto y Viviana Isabel GonzÁlez

2008 A la $1 .$. a las $2 .$. y a las...3, a jugar!!! Juegos de Tradición Oral. Santiago de Chile: Fondart.

Grugeon, Elizabeth

1993 "Gender Implications of Children's Playground Culture”, Gender and Ethnicity in Schools: Ethnographic Accounts. Martyn Hammersley y Peter Woods (editores). Londres: Routledge, pp. 11- 33 .

Hemsy de Gainza, Violeta

199675 rimas y canciones tradicionales con manos y otros gestos. Buenos Aires: Guadalupe.

HuBbard, JANE

1982 “Children's traditional games from Birdsedge: Clapping songs and their notation”, Folk Music Journal, IV/3, pp. 246-264. DOI: 10.2307/4522106

Kristeva, Julia

1997 "Bajtin, la palabra, el diálogo y la novela", Intertextualité. Desiderio Navarro (editor). UNEAC Habana: Casa de las Américas, pp. 1-24.

LADA, ULPIANO

2007 "La actio en la narrativa oral literaria", Teoría/crítica homenaje a la profesora Carmen Bobes Naves. Miguel Ángel Garrido Gallardo y Emilio Frechilla Díaz (editores). Consejo Superior de Investigaciones Científicas, Instituto de la Lengua Española. Madrid, pp. 317-334.

Martín Escobar, María Jesús

2001 "Las canciones infantiles de transmisión oral en Murcia durante el siglo XX". Tesis doctoral. Murcia: Universidad de Murcia. Disponible en: http://hdl.handle.net/10201/9714. [acceso: 3 de mayo de 2019].

Opie, Iona y Peter Opie

1985 The Singing Game. Oxford: Oxford Press.

Pelegrín, Ana

1992 "Juegos y poesía popular en la literatura infantil y juvenil (1750-1987)". Tesis doctoral. Madrid: Universidad Complutense de Madrid.

Peña, Manuel.

1999 Juguemos al hilo de oro. Folclor infantil chileno. Santiago de Chile: Arrayán Editores.

Pérez Ortega, Juan.

1976 Música Folklórica Infantil Chilena. Valparaíso: Ediciones Universitarias de Valparaíso.

Plath, Oreste

1946 Folklore Chileno: Aspectos populares infantiles. Santiago: Prensas de la Universidad de Chile.

2009 Los juegos en Chile: aproximación histórica-folclórica. Santiago de Chile: Fondo de Cultura Económica.

Rice, Tiмотну

2001 "Hacia la remodelación de la etnomusicología”, Las culturas musicales: lecturas de etnomusicología. Francisco Cruces Villalobos (coordinador). Madrid: Trotta, pp. 155-180. 
RIERA, JOANNA

2013 "Don Federico mató a su mujer y altres cançons de picar: un espai de construcción, negociació i apropiació de la cultura”. Tesina de máster. RECERCAT: Universitat Autònoma de Barcelona.

Riera, Joanna y Albert Casals

2014 "Cuando la música nos exime: las canciones de dar palmas como actividad de negociación cultural", Ankulegi. Revista de Antropología Social, 18, pp. 111-124.

Romero-Naranjo, Francisco Javier y Alejandro A. Romero-Naranjo

2013 "Handclapping songs and gender: an approach using the bapne method", Revista Feminismo/s, 31, pp. 205-223. DOI: 10.14198/fem.2013.21.11

Veblen, Kari K; Nathan B Kruse y Stephen J Messenger

2018 "Children's clapping games on the virtual playground", International Journal of Music Education, XXXVI/4, pp. 547-559. DOI: 10.1177/0255761418772865

WiLlet, REBEKAH

2011 "An ethnographic study of preteen girls' play with popular music on a school playground in the UK", Journal of Children and Media, V/4, pp. 341-357. DOI: 10.1080/17482798.2011.587146 